ARTICLE

\title{
Single molecule analysis reveals monomeric XPA bends DNA and undergoes episodic linear diffusion during damage search
}

\author{
Emily C. Beckwitt ${ }^{1,2}$, Sunbok Jang ${ }^{2,3}$, Isadora Carnaval Detweiler ${ }^{4}$, Jochen Kuper ${ }^{5}$, Florian Sauer (D) ${ }^{5}$, \\ Nina Simon ${ }^{6}$, Johanna Bretzler ${ }^{6}$, Simon C. Watkins (1) ${ }^{7}$, Thomas Carell (1) $^{6}$, Caroline Kisker ${ }^{5}$ \& \\ Bennett Van Houten (1) 2,3凶
}

Nucleotide excision repair (NER) removes a wide range of DNA lesions, including UVinduced photoproducts and bulky base adducts. XPA is an essential protein in eukaryotic NER, although reports about its stoichiometry and role in damage recognition are controversial. Here, by PeakForce Tapping atomic force microscopy, we show that human XPA binds and bends DNA by $\sim 60^{\circ}$ as a monomer. Furthermore, we observe XPA specificity for the helix-distorting base adduct $\mathrm{N}$-(2'-deoxyguanosin-8-yl)-2-acetylaminofluorene over nondamaged dsDNA. Moreover, single molecule fluorescence microscopy reveals that DNAbound XPA exhibits multiple modes of linear diffusion between paused phases. The presence of DNA damage increases the frequency of pausing. Truncated XPA, lacking the intrinsically disordered $\mathrm{N}$ - and $\mathrm{C}$-termini, loses specificity for DNA lesions and shows less pausing on damaged DNA. Our data are consistent with a working model in which monomeric XPA bends DNA, displays episodic phases of linear diffusion along DNA, and pauses in response to DNA damage.

\footnotetext{
${ }^{1}$ Program in Molecular Biophysics and Structural Biology, University of Pittsburgh, Pittsburgh, PA 15260, USA. ${ }^{2}$ UPMC Hillman Cancer Center, Pittsburgh, PA 15213, USA. ${ }^{3}$ Department of Pharmacology and Chemical Biology, University of Pittsburgh, Pittsburgh, PA 15261, USA. ${ }^{4}$ Department of Chemical Engineering, University of Pittsburgh, Pittsburgh, PA 15261, USA. ${ }^{5}$ Rudolf Virchow Center for Experimental Biomedicine, Institute for Structural Biology, University of Würzburg, 97080 Würzburg, Germany. ${ }^{6}$ Center for Integrated Protein Science at the Department of Chemistry, Ludwig Maximillian University of Munich, 81377 Munich, Germany. ${ }^{7}$ Center for Biologic Imaging, University of Pittsburgh, Pittsburgh, PA 15261, USA. ${ }^{凶}$ email: vanhoutenb@upmc.edu
} 
$\mathrm{N}$ ucleotide excision repair (NER) is a highly conserved DNA repair pathway that, through a series of damage recognition and verification steps, is able to act on a wide range of DNA lesions. In humans, this process involves approximately 30 proteins, working together to protect our genomes from the damaging effects of UV radiation and chemical agents like cisplatin, polycyclic aromatic hydrocarbons, and aromatic amines. UV radiation causes formation of two major lesions in DNA: the cyclobutane pyrimidine dimer (CPD) and 64 photoproduct (6-4PP), at a ratio of approximately three to one ${ }^{1}$. NER can be initiated in two general ways ${ }^{2,3}$. During transcription-coupled (TC) NER, RNA polymerase stalls at a lesion and is recognized by CSA and CSB, which promote removal of the polymerase from the damage site and recruitment of subsequent repair proteins. Recently, broader roles for CSA and CSB in proteasome-mediated degradation of an immediate early gene product and transcription restart after UV have been reported ${ }^{4}$. Global genome (GG) NER is initiated by UV-DDB and/or XPC-RAD23B when they recognize the presence of a lesion at any site in the chromatin. The two pathways converge for a damage verification step, where the TFIIH helicase complex unwinds the DNA and ensures that damage is present. The endonucleases XPF-ERCC1 and XPG cut the DNA sequentially, removing 24-32 bases while DNA polymerase $(\delta, \varepsilon$, or $\kappa)$ and ligase (I or III) fill in the gap.

XPA is a protein that plays an essential role in both TC and GG NER. Patients with reported mutations in the XPA gene experience some of the most severe phenotypes of a disease called xeroderma pigmentosum (XP) and are at a significantly increased risk for skin cancer ${ }^{5}$. The exact function of XPA in NER remains controversial, as evidence exists for multiple roles. Relative to non-damaged dsDNA, XPA displays specificity for UV-irradiated $\mathrm{DNA}^{6}, \quad 6-4 \mathrm{PPs}^{7}, \quad \mathrm{~N}$-(2'-deoxyguanosin-8-yl)-2-acetylaminofluorene $(\mathrm{dG}-\mathrm{C} 8-\mathrm{AAF})^{8-10}$, cisplatin ${ }^{11}$, non-hybridized bases ${ }^{12,13}$, and other artificially distorted substrates ${ }^{13,14}$. XPA also binds preferentially to partially single-stranded DNA and forked substrates $^{15,16}$. Early literature on the function of XPA in NER suggests that it is involved in initial steps of damage recognition ${ }^{17,18}$. Additional data place XPA at the damage verification step, interacting with and enhancing damage specificity of TFIIH ${ }^{19-21}$, or even later in the pathway ${ }^{22}$, acting as a scaffold and interacting with other NER proteins ${ }^{23}$, including $\mathrm{RPA}^{24}$. Importantly, it has been suggested that damage recognition in NER, which needs to accommodate a diverse range of structures, is accomplished via a "discrimination cascade" involving multiple proteins with imperfect selectivity $7,25,26$. In support of this model, XPA enhances the damage specificity of TFIIH by promoting both its translocation along non-damaged DNA and stalling on damaged $\mathrm{DNA}^{20}$. As such, it remains of significant interest to investigate how XPA interacts with DNA lesions.

There is limited structural data for full-length XPA, due to large regions of conserved intrinsic disorder (Supplementary Fig. 1a), particularly in the N- and C-termini ${ }^{27-29}$. The intrinsically disordered regions of XPA may function in protein-DNA and/or protein-protein interactions ${ }^{29}$. Human XPA contains 273 amino acids with a molecular weight of $31.4 \mathrm{kDa}$. The minimal DNA-binding domain (DBD) was first identified by Tanaka and colleagues $^{11}$, and later expanded to include residues 98-239 (ref. ${ }^{30}$ ), covering about half of the total protein length and a zincfinger motif. Available XPA structures include early solution NMR studies of human XPA DBD ${ }^{31,32}$, a recent crystal structure of the extended human $\mathrm{DBD}^{33}$, co-crystal structures of yeast Rad14 (XPA homolog) DBD on damaged DNA ${ }^{10,34}$, and a cryoelectron microscopy structure of the complex formed between $\mathrm{XPA}, \mathrm{TFIIH}$, and $\mathrm{DNA}^{21}$. At present, there is no structural information regarding the $\mathrm{N}$ - and C-termini of XPA or its homologs in the RCSB Protein Data Bank. The Rad14 DBD structures show that the protein can bind DNA as a dimer flanking the damage site and produces a $70^{\circ}$ bend in the DNA $^{10,34}$. This result supports previous studies which concluded that XPA binds DNA as a homodimer ${ }^{8,9,35}$. XPA stoichiometry both on and off of DNA remains controversial as others have reported monomeric binding ${ }^{15,21,36}$, or that stoichiometry is dependent on the DNA substrate ${ }^{16}$.

We therefore set out to resolve four fundamental issues regarding how XPA interacts with sites of damage in DNA: (a) specificity for DNA lesions embedded in long DNA substrates, (b) stoichiometry of binding, (c) induced DNA bending at lesions and/or non-specific sites, and (d) how XPA examines DNA for damage. First, atomic force microscopy (AFM) is used to assess binding specificity of lesions embedded in long DNA substrates, stoichiometry, and DNA bending. To accomplish this, we validate a new PeakForce Tapping ${ }^{\circledR}$ AFM mode for calculating the molecular weight of small proteins bound to DNA. Second, we use single molecule fluorescence microscopy to follow how quantum dot-labeled full-length and truncated XPA (lacking the intrinsically disordered domains) interrogate DNA for damage in real time. Based on these data, we propose a model of XPA episodic motion in which different conformational states of the protein are associated with different modes of DNA target search and the presence of helix-distorting DNA damage stabilizes tighter binding.

\section{Results}

XPA binds specifically to a dG-C8-AAF lesion. We first confirmed that XPA recognizes AAF-adducted DNA by electrophoretic mobility shift assay (EMSA) as reported by others ${ }^{8-10,12}$. We generated binding isotherms of XPA by incubating a $37 \mathrm{bp}$ DNA duplex $(8 \mathrm{nM})$ with or without a single dG-C8-AAF adduct $\left(\mathrm{AAF}_{37}\right.$ and $\mathrm{ND}_{37}$, respectively) and increasing amounts of purified full-length human XPA (His-flXPA-StrepII, Supplementary Fig. $1 \mathrm{~b})$. The apparent equilibrium dissociation constant $\left(K_{\mathrm{D}}\right)$ was $253 \pm 14 \mathrm{nM}$ (best fit value \pm standard error of the fit) for $\mathrm{ND}_{37}$ and $109 \pm 5 \mathrm{nM}$ for $\mathrm{AAF}_{37}$, an approximately 2.3-fold difference (Supplementary Fig. 1c, e, g). Because $\mathrm{AAF}_{37}$ contains only one specific site among 36 non-damaged bp, this difference can be multiplied by a factor of 37 to account for non-specific binding to the $\mathrm{AAF}_{37}$ substrate ${ }^{17,37}$. This results in approximately 85 -fold specificity for dG-C8-AAF over non-damaged DNA, in good agreement with a previously reported specificity of XPA for 6 $4 \mathrm{PP}^{17}$. We also found the specificity for a CPD lesion to be $\sim 44-$ fold (Supplementary Fig. 1d, i). Furthermore, at higher XPA concentrations, a second band of higher molecular weight appeared, indicating binding of an additional XPA protein. It is important to note that any affinity of XPA for DNA ends could obscure EMSA results in terms of (a) specificity, as end-binding (a common feature of DNA-binding proteins ${ }^{38,39}$ ) would increase overall binding on both substrates, thereby lowering the apparent specificity for the lesion, and (b) stoichiometry, as separate XPA proteins bound to the lesion and the end of the DNA would migrate the same as a true dimer in the gel. If XPA has fairly high non-specific binding affinity, then embedding a lesion in a long stretch of non-damaged DNA might pose difficulties in damage recognition.

We therefore turned to AFM to study XPA binding to a 538 bp DNA substrate with or without a single dG-C8-AAF lesion. The small size of XPA presents challenges in terms of resolution and ability to visualize XPA bound to DNA using AFM in tapping mode; we thus adopted the use of PeakForce Tapping mode (Bruker) with a $2 \mathrm{~nm}$ tip to achieve improved resolution and reduced sample deformation ${ }^{40,41}$. Using this method, we were 

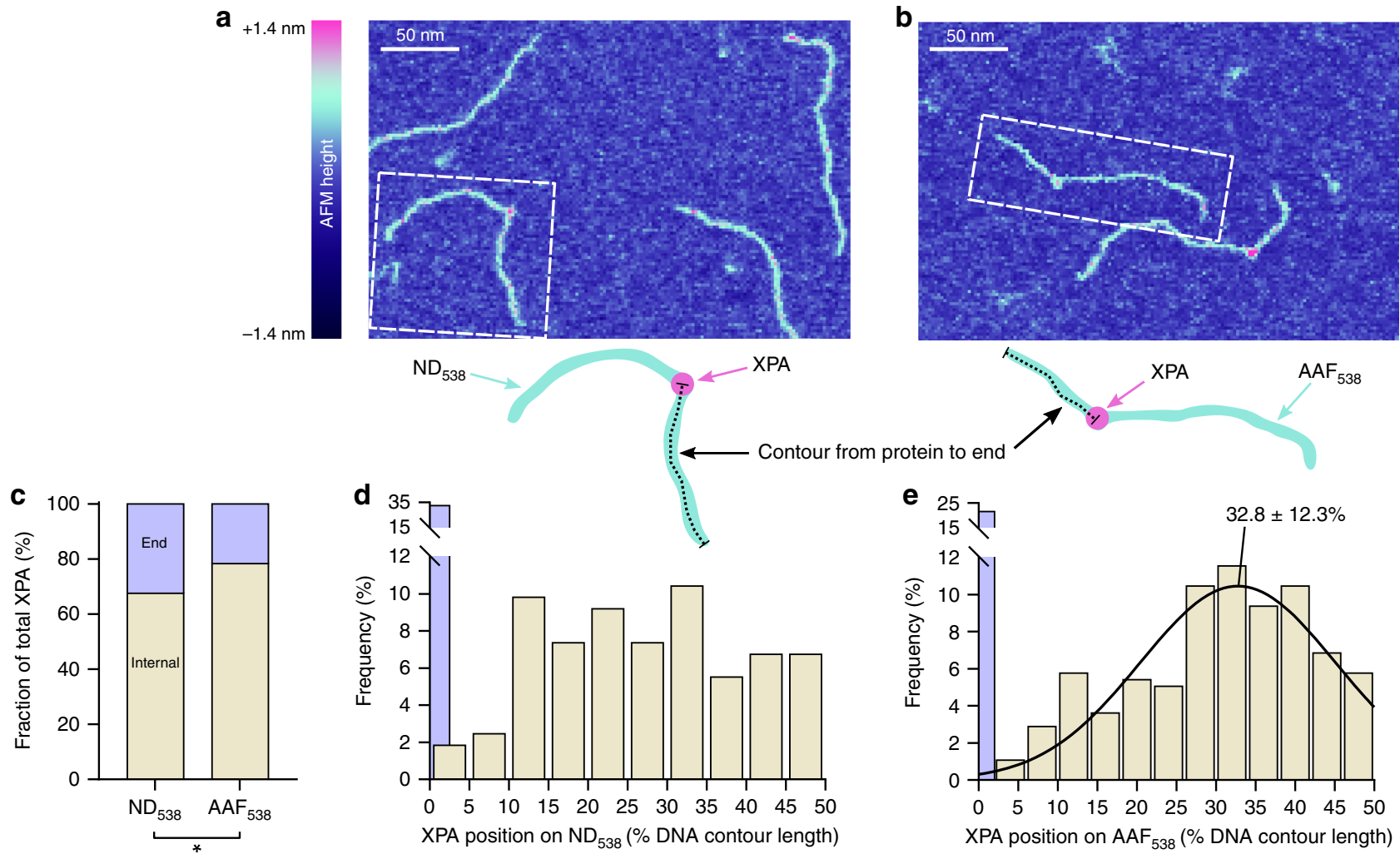

Fig. 1 XPA binds specifically to a dG-C8-AAF lesion. a, b Representative AFM image of XPA bound to a non-damaged 538 bp DNA substrate (a, ND 538 ) or a 538 bp DNA with a single dG-C8-AAF lesion at $30 \%$ from one end $\left(\mathbf{b}, A A F_{538}\right)$. The dashed white line indicates the example in the cartoon below. Binding position was measured between the center of the protein to the closest DNA end as a percentage of total DNA contour length. $\mathbf{c}$ Percentage of XPA bound to DNA at ends (lavender) or internally (tan) on $\mathrm{ND}_{538}\left(n=163\right.$ particles) and $\mathrm{AAF}_{538}\left(n=277\right.$ particles). ${ }^{*} p=0.0118$ by $\chi^{2}$ test. $\mathbf{d}$ Histogram showing the distribution of internally bound XPA ( $n=110$ particles) position on ND $\mathrm{N}_{538}$. End-binders are shown in lavender. e Histogram and Gaussian fitting of internally bound XPA ( $n=217$ particles) positions on $\mathrm{AAF}_{538}$. End binders are shown in lavender (not included in Gaussian fit). Gaussian is labeled with mean and s.d.

able to clearly recognize XPA bound to DNA by the increased AFM height and width of the complex (Fig. 1a, b).

Full-length human XPA (His-flXPA, Supplementary Fig. 1b, 1$4 \mu \mathrm{M})$ was incubated with a non-damaged $538 \mathrm{bp}$ DNA substrate $\left(\mathrm{ND}_{538}, 100 \mathrm{nM}\right)$ and three-dimensional images were obtained using PeakForce Tapping AFM. Of all the complexes observed, $33 \%$ were bound to the ends of the DNA substrate (Fig. 1c); we observed no instances of XPA bound to both ends. For the remaining internally-bound proteins, position along the DNA molecule was measured as a percentage of the total contour length of the DNA, which revealed no preference for a specific internal site (Fig. 1d).

XPA (His-flXPA) was then incubated with a 538 bp DNA substrate of the same sequence as $\mathrm{ND}_{538}$ but with a single dG-C8$\mathrm{AAF}$ lesion at $30 \%$ from the 3' end $\left(\mathrm{AAF}_{538}\right)$. On this substrate, only $22 \%$ of bound XPA proteins were found at the DNA ends. We also observed an increased frequency of complexes found near the lesion, at the expense of end-binders and other nonspecific complexes (Fig. 1e). A Gaussian was fit to the distribution of binding positions with a mean of $32.8 \pm 12.3 \%$ (mean \pm s.d. of Gaussian). This spread of values is similar to others we have reported for lesion-binding proteins ${ }^{42}$. Using the method of Erie and colleagues to assess specificity without confounding endbinders $^{38}$, we find that XPA has a specificity for dG-C8-AAF of $\sim 660$ (Supplementary Note 1, Supplementary Fig. 2). Based on these data, it is clear that XPA is able to bind non-specifically to DNA (at ends and non-damaged sequences). However, the protein does exhibit specificity for an AAF adduct embedded in a long DNA substrate and binds preferentially at such a site.
XPA is a monomer in the absence of DNA. To investigate the question of XPA stoichiometry, we first sought to clarify the oligomeric status of the free protein. While there is support that XPA is a monomer in solution ${ }^{43-45}$, there have also been reports that it forms dimers and higher oligomers ${ }^{35}$. AFM has been successfully used to determine protein stoichiometry due to the linear relationship between AFM volumes of globular proteins and their molecular weight ${ }^{46,47}$. Full-length human XPA (HisflXPA, $32.6 \mathrm{kDa}$ ) was diluted to $40 \mathrm{nM}$ and deposited on mica for imaging by PeakForce Tapping AFM in air. Volumes of the particles were measured and the data fit a Gaussian distribution centered at $30.3 \pm 15.4 \mathrm{~nm}^{3}$ (Fig. 2a).

In order to translate this volume into molecular weight, and thus protein stoichiometry, we generated a standard curve using monomeric proteins of known sizes (Fig. 2b). HMGB1 (25 kDa), APE1 (37 kDa with His tag), DNA polymerase $\beta(\mathrm{Pol} \beta, 42.8 \mathrm{kDa}$ with His tag), and $\mathrm{UvrD}(85.6 \mathrm{kDa}$ with His tag) were adsorbed at $40 \mathrm{nM}$ on mica and imaged by PeakForce Tapping AFM (Supplementary Fig. 3). Measured AFM volumes of these proteins were plotted against their known molecular weight and fit using least-squares linear regression: Volume $=(\mathrm{MW} \times 1.14)-2.00$. Using this equation, the measured volumes for XPA correspond to $28.4 \pm 15.3 \mathrm{kDa}$, close to the expected molecular weight of $32.6 \mathrm{kDa}$ for the monomer. There was no significant population of XPA corresponding to the dimer size.

To confirm that XPA is a monomer at higher protein concentrations, we performed size exclusion chromatography coupled with multiangle light scattering (SEC-MALS). At $65 \mu \mathrm{M}$ and $80 \mu \mathrm{M}$, purified XPA (His-flXPA-StrepII, $33.9 \mathrm{kDa}$ ) eluted in 
a
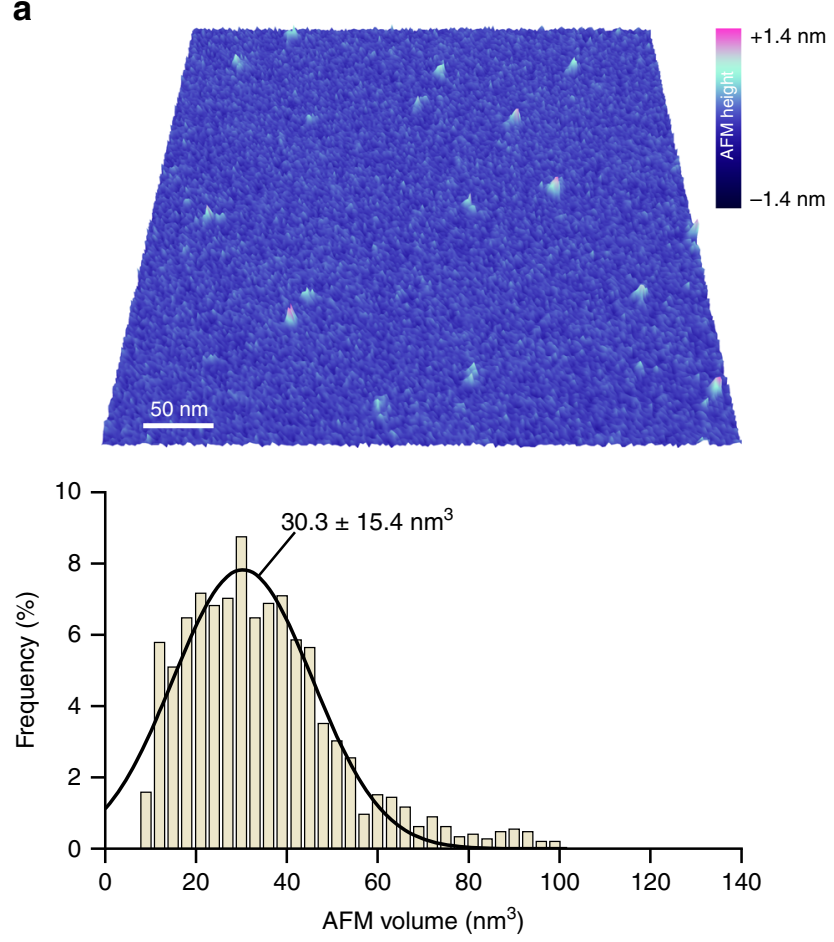

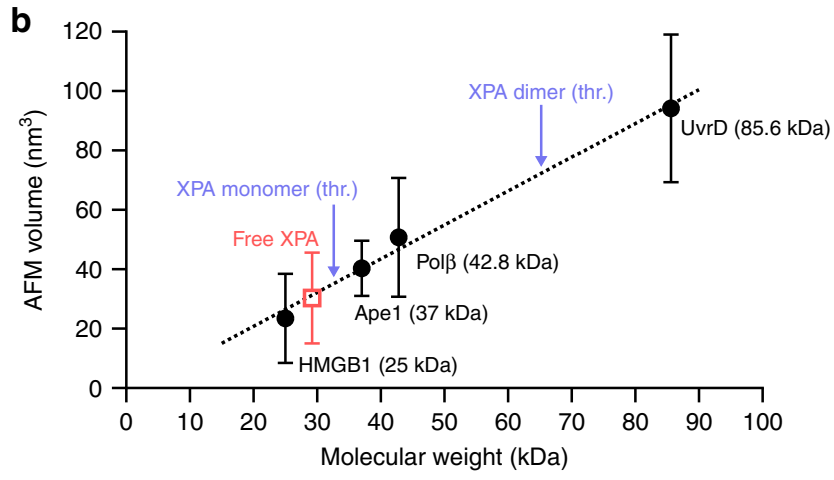

C

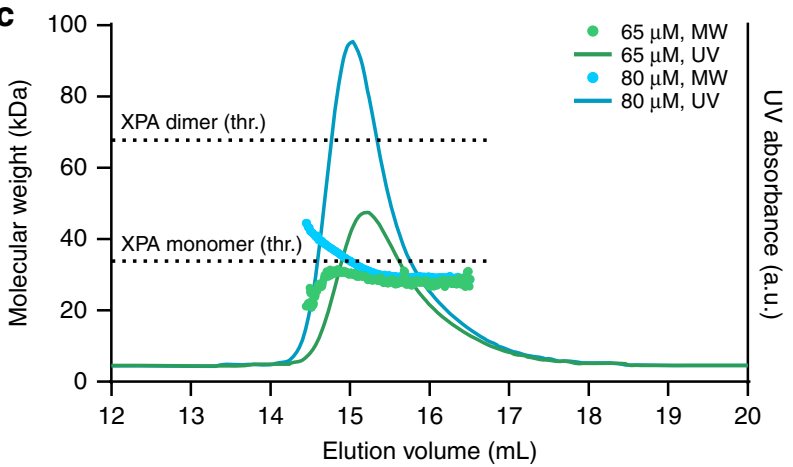

Fig. 2 XPA is a monomer in the absence of DNA. a Top, representative 3D AFM image of free XPA. Bottom, histogram and Gaussian fit of free XPA molecules imaged by AFM ( $n=1451$ particles). Gaussian is labeled with mean and s.d. b Standard for calculating molecular weight from AFM volumes. Volumes of free proteins imaged by PeakForce Tapping AFM were calculated and respective histograms were fit by Gaussian distributions. Solid black circles, proteins used to generate the standard plotted against their known MW (results and $n$ values for each in Supplementary Fig. 3). Dashed line, linear regression, resulting in the calibration curve: Volume $\left(\mathrm{nm}^{3}\right)=1.14 \times \mathrm{MW}(\mathrm{kDa})-2.00 . R^{2}=0.990$. Purple arrows point to theoretical (thr.) volumes for the purified His-flXPA monomer $(32.6 \mathrm{kDa})$ and dimer $(65.2 \mathrm{kDa})$. Open red square, experimental His-flXPA AFM volume (see a), corresponding to a molecular weight of $28.4 \pm 15.3 \mathrm{kDa}$. Errors bars indicate s.d. of the Gaussian distribution. c Molecular weight (MW) determination by SEC-MALS of XPA at $65 \mu \mathrm{M}$ (green) and $80 \mu \mathrm{M}$ (blue). Theoretical molecular weights for the purified His-flXPA-Strepll monomer (33.9 kDa) and dimer (67.8 kDa) are indicated by dashed lines.

a single major peak, with a molecular weight corresponding principally to a monomer (Fig. 2c). By both methods, the apparent molecular weight was a few $\mathrm{kDa}$ less than the theoretical value based on the sequence with tags, potentially due to protein conformation. Together, these data clearly indicate that XPA (40 $\mathrm{nM}-80 \mu \mathrm{M})$ predominantly exists as a monomeric species in solution.

XPA binds non-damaged DNA and dG-C8-AAF as a monomer. Previous reports suggest that XPA may bind DNA as a homodimer ${ }^{9,35}$ while others indicate monomeric binding ${ }^{15,21,36}$. AFM offers the unique ability to distinguish between distinct complexes (e.g., one protein at a DNA end and one protein at a lesion) and true dimerization. Therefore, we measured the AFM volumes of XPA bound to DNA in order to determine stoichiometry. Because XPA is a small protein, we expected the DNA to contribute a significant amount of volume to the total complex. Based on published studies ${ }^{48}$, we developed a method to determine the size of the DNA within the complex and subtract its volume to obtain the volume of XPA alone, and validated this using two proteins known to bind DNA as monomers, APE1 and Polß (Supplementary Note 2, Supplementary Fig. 4).

Having confirmed that we would be able to distinguish XPA monomers and dimers on DNA, we measured AFM volumes for XPA (His-flXPA, $32.6 \mathrm{kDa}$ ) bound to $\mathrm{ND}_{538}$ and $\mathrm{AAF}_{538}$ (Fig. 3). In some cases, we observed multiple binding events on the same DNA molecule; these were measured individually if there was a clear stretch of unbound DNA between them. XPA bound to
$\mathrm{ND}_{538}$ had a distribution of AFM volumes centered at $28.4 \pm 12.7$ $\mathrm{nm}^{3}$ (mean \pm s.d. of the Gaussian), corresponding to $26.7 \pm 12.9$ $\mathrm{kDa}$ (Fig. 3b). The volumes of internally and end-binding proteins had similar distributions. XPA bound to $\mathrm{AAF}_{538}$ had a distribution of volumes centered at $31.0 \pm 12.9 \mathrm{~nm}^{3}$, corresponding to $29.0 \pm 13.1 \mathrm{kDa}$ (Fig. 3d). Again, the volumes of internallybinding (either near the lesion or not) and end-binding proteins had similar distributions. Thus, our AFM data show that, regardless of where XPA binds DNA, it does so as a monomer. We did not observe a significant population corresponding to a dimer.

XPA bends DNA $\sim \mathbf{6 0}^{\circ}$. Having shown that XPA binds to damaged and non-damaged DNA as a monomer, we next asked whether XPA induces a bend at the dG-C8-AAF site. We first sought to determine if the dG-C8-AAF lesion itself introduces any flexibility into the DNA helix. Because this lesion was placed at $30 \%$ from the 3 ' end of the $\mathrm{AAF}_{538}$ substrate, we measured the DNA bend angle at this site for unbound DNA. Note that while there is a single lesion in our damaged substrate, we measured the angle at $30 \%$ from both ends (resulting in two angles per DNA molecule) because, under the current conditions, we are unable to differentiate between the 5' and 3' end of the molecule. As a negative control we measured the DNA angle at $30 \%$ from each end of $\mathrm{ND}_{538}$ (Fig. 4a), and found a distribution centered around $0^{\circ}$ (Fig. 4c). The distribution for the dG-C8-AAF-modified DNA, $\mathrm{AAF}_{538}$, showed the emergence of a second population of bend angles (Fig. 4b, d). A double Gaussian fit to the data describes two 
a

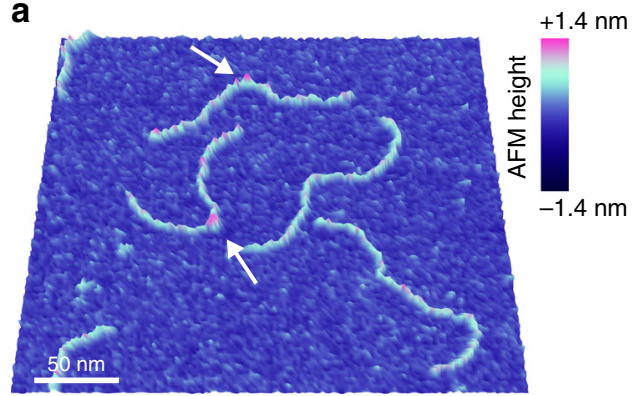

C

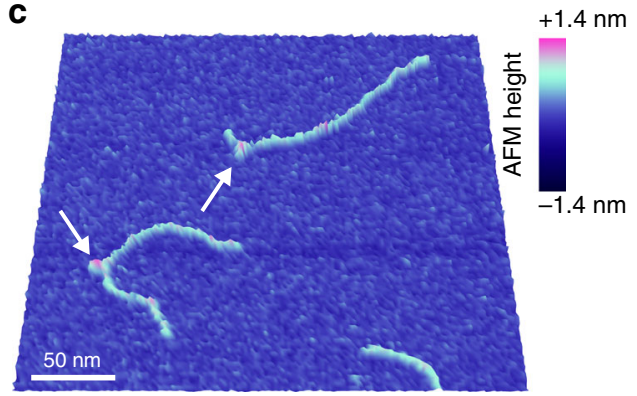

b
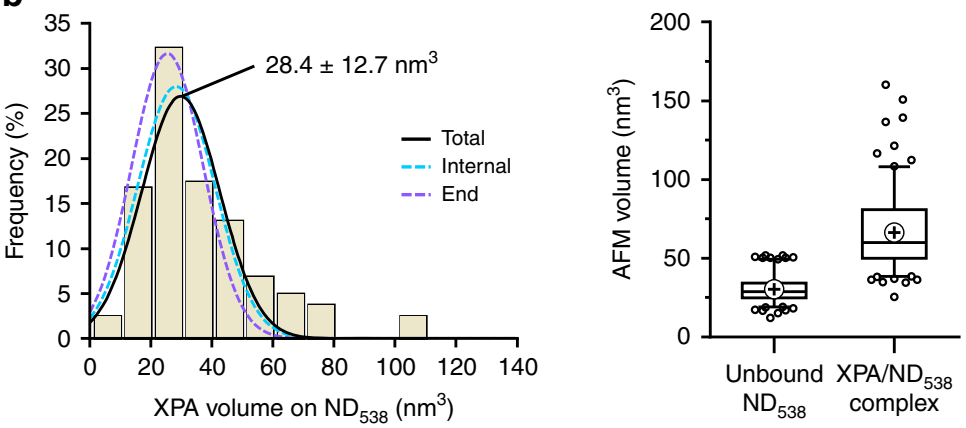

d

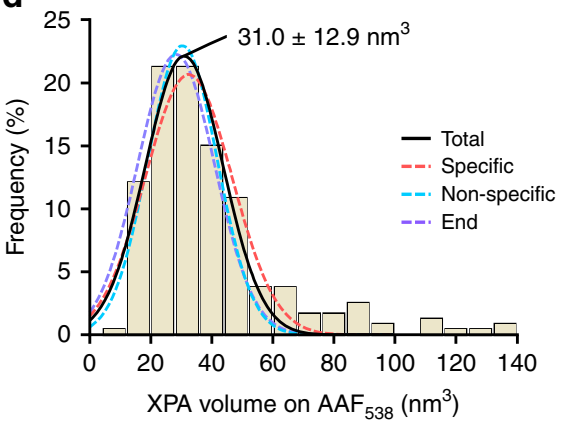

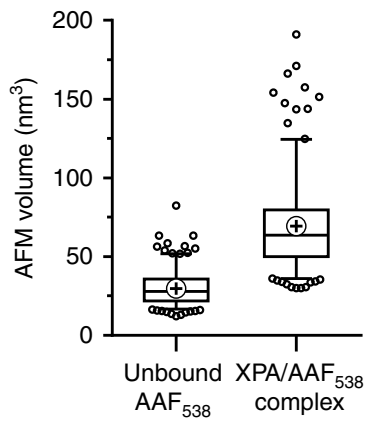

Fig. 3 XPA binds non-damaged DNA and dG-C8-AAF modified DNA as a monomer. a, c Representative 3D AFM image of XPA bound to 538 bp nondamaged DNA (a, ND 538 ) or 538 bp DNA with a single dG-C8-AAF adduct at $30 \%$ from one end (c, AAF 538 ). White arrows point to XPA bound to DNA. b Left, histogram showing distribution of AFM volumes of all XPA molecules bound to $\mathrm{ND}_{538}(n=161$ particles) with Gaussian fit (solid black line, labeled with mean \pm s.d. of the distribution). AFM volume corresponds to $26.7 \pm 12.9 \mathrm{kDa}$, using the standard shown in Fig. $2 \mathrm{~b}$. Dashed cyan line, Gaussian fit to the sub-fraction of non-specifically bound XPA (i.e., all internal complexes, $n=108$ ); centered at $29.9 \mathrm{~nm}^{3}$ (s.d. $12.8 \mathrm{~nm}^{3}$ ), corresponding to $28.0 \pm 13.0 \mathrm{kDa}$. Dashed purple line, Gaussian fit to the sub-fraction of XPA bound at DNA ends $\left(n=53\right.$ ); centered at $25.5 \mathrm{~nm}^{3}$ (s.d. $11.7 \mathrm{~nm}^{3}$ ), corresponding to $24.1 \pm 12.0 \mathrm{kDa}$. Right, box and whisker plots (5-95 percentile) of unbound DNA and total complex volume measurements. d Left, histogram showing the distribution of AFM volumes of all XPA proteins ( $n=235$ particles) bound to $\mathrm{AAF}_{538}$ with a Gaussian fit (solid black line). The AFM volume corresponds to $29.0 \pm 13.1 \mathrm{kDa}$. Dashed red line, Gaussian fit to the sub-fraction of XPA bound between 20 and $40 \%$ of the DNA contour length ("specific," $n=58$ ); centered at 32.4 nm 3 (s.d. $14.4 \mathrm{~nm}^{3}$ ), corresponding to $30.2 \pm 14.4 \mathrm{kDa}$. Dashed cyan line, Gaussian fit to the sub-fraction of XPA bound internally but at positions away from the lesion ("non-specific," $n=84$ ); centered at $30.5 \mathrm{~nm}^{3}$ (s.d. $11.4 \mathrm{~nm}^{3}$ ), corresponding to $28.5 \pm 11.8 \mathrm{kDa}$. Dashed purple line, Gaussian fit to the sub-fraction of XPA bound at DNA ends $(n=51)$; centered at $28.3 \mathrm{~nm}^{3}$ (s.d. $13.0 \mathrm{~nm}^{3}$ ), corresponding to $26.6 \pm 13.2 \mathrm{kDa}$. Right, box and whisker plots (5-95 percentile) of unbound DNA and total complex volume measurements.

populations at $10.5 \pm 7.0^{\circ}$ and $34.8 \pm 10.6^{\circ}$. These data are consistent with the smaller angle being the unmodified site and the larger angle being the result of flexibility introduced by dG-C8$\mathrm{AAF}^{49,50}$.

We next asked if XPA bends the DNA. Our AFM data show that XPA bends both non-damaged (Fig. 4e) and AAF-adducted (Fig. 4f) DNA. DNA angles were measured at all sites of internally-bound XPA. On $\mathrm{ND}_{538}$, XPA induced a bend angle of $54.0 \pm 30.1^{\circ}$ (Fig. $4 \mathrm{~g}$ ). On $\mathrm{AAF}_{538}$, XPA induced a bend angle of $58.6 \pm 26.8^{\circ}$; the distribution was essentially the same for XPA bound near the lesion or non-specifically (Fig. $4 \mathrm{~h})$. The angle is greater than that introduced by the lesion itself $\left(\sim 30^{\circ}\right)$. Together, our AFM data indicate that XPA binds preferentially to the helixbending dG-C8-AAF site and that, regardless of binding site, the complex contains a single XPA protein and the DNA is bent $\sim 60^{\circ}$.

XPA performs episodic 1D diffusion to search DNA for damage. The width of the Gaussian distribution of XPA binding position on $\mathrm{AAF}_{538}$ suggests that the protein might be dynamic on DNA and migrate some distance away from a damaged site. We have previously shown that Rad4-Rad23, which adopts a similar distribution of binding positions by AFM, performs constrained linear diffusion around a lesion ${ }^{42}$. Therefore, we next investigated whether XPA displays one-dimensional diffusion on non-damaged and damaged DNA using a single molecule DNA tightrope assay ${ }^{51,52}$.

DNA tightropes consisted of long ( $>40 \mathrm{kbp}$ ) DNA molecules suspended (elongated $\sim 90 \%$ of the DNA contour length) between beads in a flow cell. His-tagged XPA was labeled with either a streptavidin-conjugated $705 \mathrm{~nm}$ quantum dot (Qdot) and biotinylated anti-His antibody (Fig. 5a) or an anti-mouse IgG antibody-conjugated $605 \mathrm{~nm}$ Qdot and mouse anti-His antibody. Both strategies resulted in similar observed behavior (Supplementary Fig. 5e). For observation, flow was turned off and $300 \mathrm{~s}$ movies were recorded at 10-12.5 frames per second (fps) of XPA on one of four different tightrope substrates: non-damaged genomic $\lambda$ DNA (ND $\lambda)$, UV-treated $\lambda$ DNA $\left(U V \lambda_{20 \mathrm{~J}}\right.$ and $\left.\mathrm{UV} \lambda_{80 \mathrm{~J}}\right)$, and defined arrays of dG-C8-AAF (AAF $\left.\mathrm{Array}_{\text {arr }}\right)$. Exposure of $\lambda$ DNA to $20 \mathrm{~J} / \mathrm{m}^{2}\left(\mathrm{UV} \lambda_{20 \mathrm{~J}}\right)$ or $80 \mathrm{~J} / \mathrm{m}^{2}\left(\mathrm{UV} \lambda_{80 \mathrm{~J}}\right) 254 \mathrm{~nm} \mathrm{UV-C}$ radiation results in a lesion density of approximately one UV photoproduct every $2.2 \mathrm{kbp}$ or $550 \mathrm{bp}$, respectively (ref. ${ }^{53}$ ). Because UV-C radiation leads to formation of lesions comprising $\sim 75 \%$ CPDs (relatively non-distorting to DNA helix) and $\sim 25 \%$ 6-4PPs (which induce a $44^{\circ}$ bend in DNA) ${ }^{1,54}$, we expect $U V \lambda_{80}$ to contain one $6-4 \mathrm{PP}$ every $\sim 2.2 \mathrm{kbp}$. AAF arrays were prepared via end-to-end ligation of a $2030 \mathrm{bp}$ fragment of linear DNA with a single site-specific dG-C8-AAF modification ${ }^{53,55}$. Kymographs were first categorized into four groups: stationary/persistent, stationary/dissociated, motile/persistent, and motile/dissociated. 

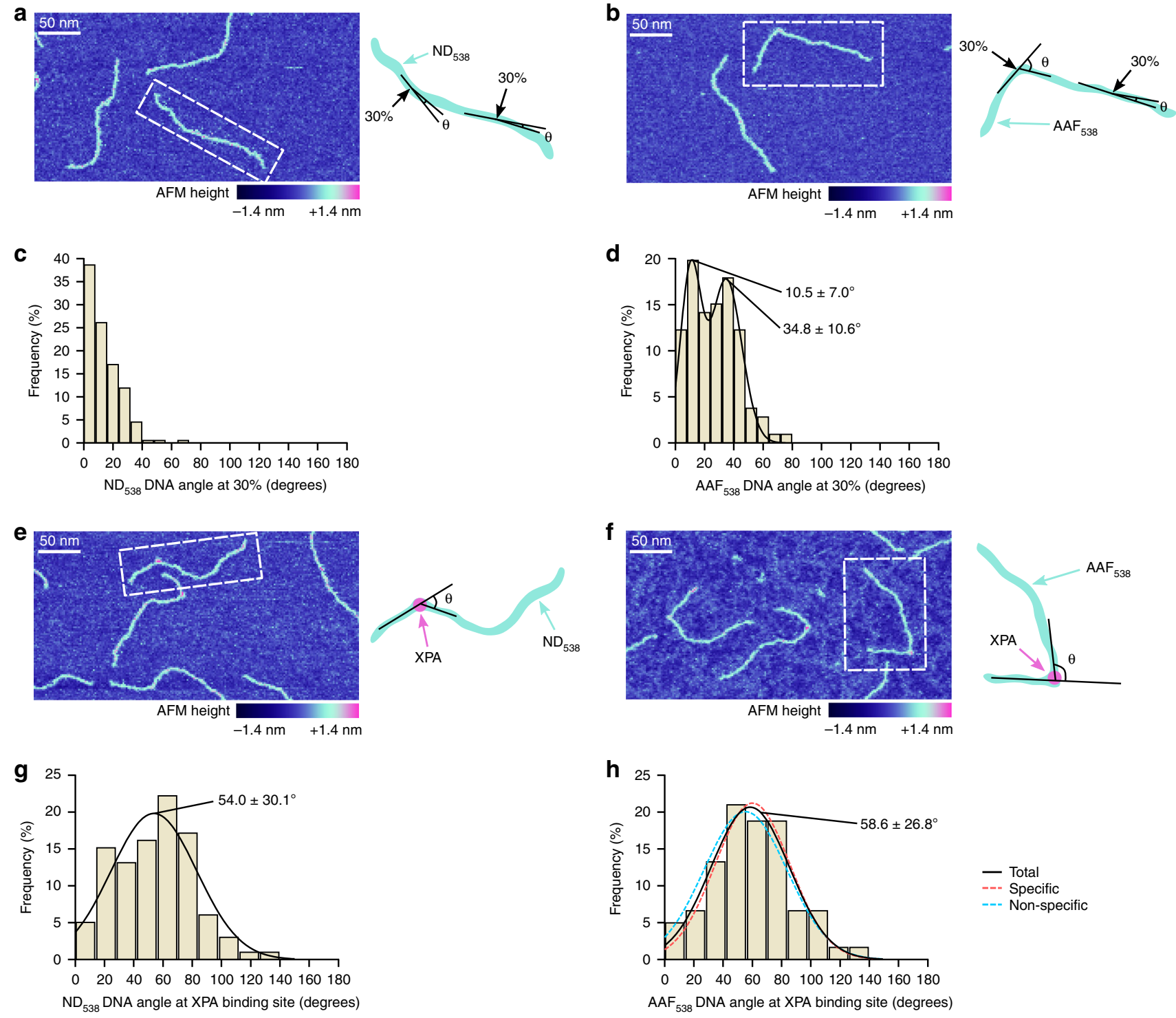

Fig. 4 dG-C8-AAF bends DNA $\sim \mathbf{3 5}^{\circ}$ and XPA bends DNA $\sim \mathbf{6 0}^{\circ}$. a, b Representative AFM image of free 538 bp non-damaged DNA (a, ND 538 ) or free 538 bp DNA with a single dG-C8-AAF adduct at $30 \%$ from one end $\left(\mathbf{b}, \mathrm{AAF}_{538}\right)$. Dashed white line indicates the example in the cartoon to the right. Angles were measured at sites $30 \%$ of the total DNA contour length from each end and are reported as the $\theta$ angle (supplement to internal DNA angle). c Histogram of the inherent DNA bend angle of non-damaged DNA ( $n=176$ angles). $\mathbf{d}$ Histogram and double Gaussian fitting of the inherent DNA bend angle of AAF-adducted DNA ( $n=106$ angles). Each peak of the Gaussian is labeled as mean \pm s.d. e, $\mathbf{f}$ Representative AFM image of XPA bound to ND 538 (e) or $\mathrm{AAF}_{538}(\mathbf{f})$. The dashed white line indicates the example in the cartoon to the right. Angles were measured at sites of bound XPA and are reported as the $\theta$ angle. $\mathbf{g}$ Histogram and Gaussian fitting showing the distribution of DNA bend angles at all sites of internally bound XPA on ND $538(n=99$ angles). h Histogram showing distribution of DNA bend angles at all sites of internally bound XPA on $\mathrm{AAF}_{538}$ ( $n=181$ angles) with Gaussian fit (solid black line). Gaussian is labeled as mean \pm s.d. Dashed red line, Gaussian fit to the sub-fraction of angles at XPA sites between 20 and $40 \%$ of the DNA contour length ("specific," $n=116$ ); centered at $60.2^{\circ}$ (s.d. $25.7^{\circ}$ ). Dashed cyan line, Gaussian fit to the sub-fraction of angles at sites of XPA bound internally but at positions away from the lesion ("non-specific," $n=65$ ); centered at $55.3^{\circ}$ (s.d. $28.5^{\circ}$ ).

Motility was defined as linear displacement greater than $130 \mathrm{~nm}$ ( $380 \mathrm{bp}$ or three pixels, see Methods) over the course of observation. XPA was primarily stationary $(60-70 \%$ of the molecules) on all tightrope substrates (Fig. 5b, flXPA). Although the proportions of these broad categories do not appear to be affected by the DNA substrate, we expected the nature of diffusion to differ depending on the type and lesion density. We therefore analyzed the motile fraction in greater detail.

Unlike other repair proteins we have observed at the single molecule level ${ }^{42,53,56}$, motile XPA particles often changed their diffusive behavior multiple times during observation (Fig. $5 \mathrm{c}$,
Supplementary Movie 1). Most exhibited some periods of pausing between episodic phases of linear diffusion. We categorized the behavior of motile XPA into three distinct modes: paused (particle not moving), short-range diffusion (displacement less than $690 \mathrm{~nm}$ ), and long-range diffusion (displacement greater than $690 \mathrm{~nm}$ ). Thresholds for motile modes were chosen based on approximate distances between lesions; assuming true B-form DNA, $2030 \mathrm{bp}$ correspond to $690 \mathrm{~nm}$. Fig. $5 \mathrm{c}$ shows an example of XPA on ND $\lambda$, exhibiting all three modes; the behavior of each particle was divided into phases based on these modes. 
a

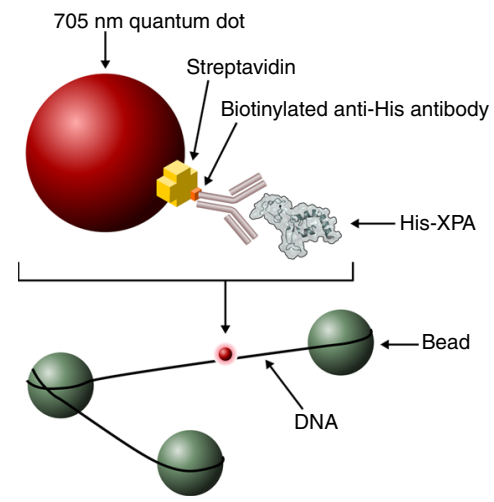

C

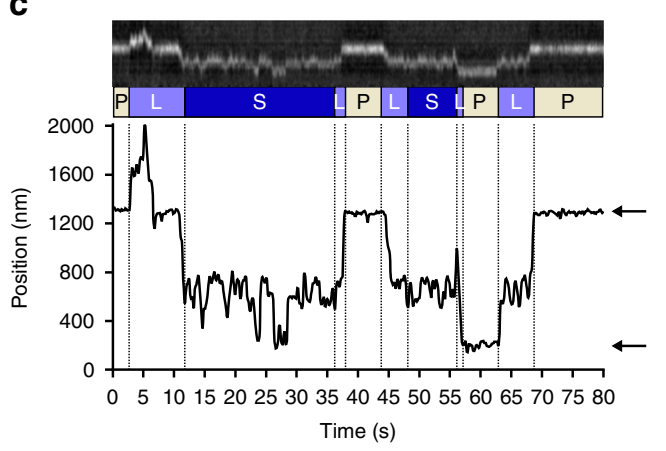

b

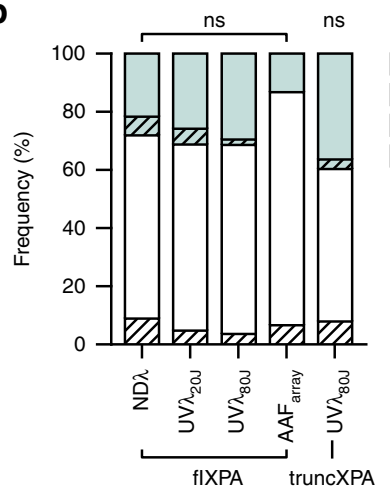

d

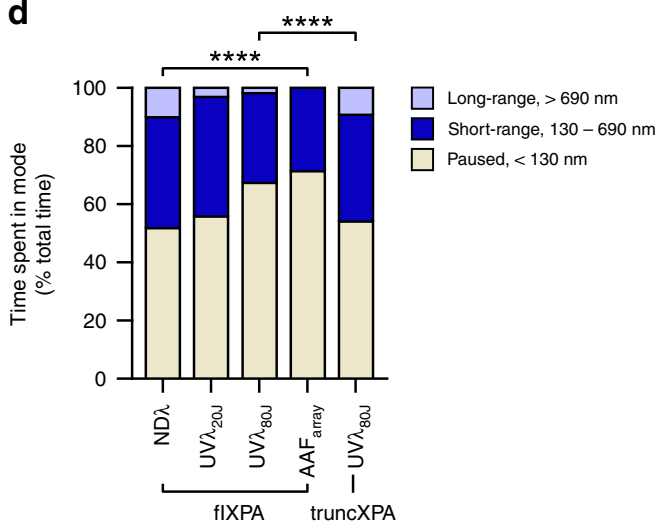

e
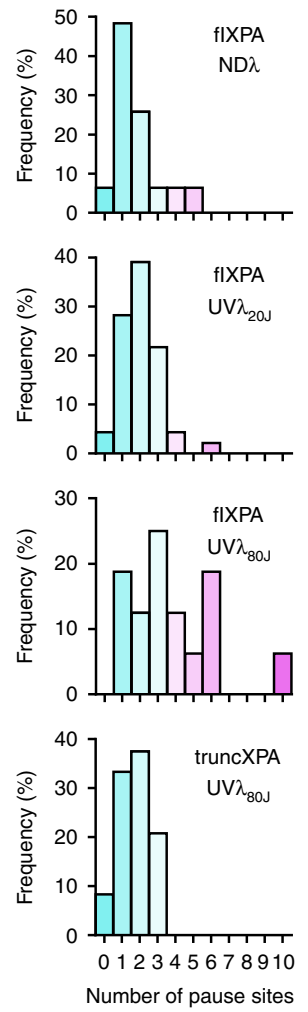

Fig. 5 XPA exhibits episodic linear diffusion on DNA tightropes. DNA damage leads to increased pausing, dependent on N-and C-termini. a Cartoon showing one strategy used for XPA labeling on DNA tightropes. His-tagged XPA is labeled with a biotinylated anti-His antibody bound to a streptavidinconjugated $705 \mathrm{~nm}$ quantum dot. See Methods for alternative labeling strategy. b Stacked bar graph showing the fraction of motile (teal) vs. stationary (white) and persistent (solid) vs. dissociating (diagonal lines) particles of full-length XPA (flXPA) on non-damaged $\lambda\left(N D \lambda, n=124\right.$ particles), $20 \mathrm{~J} / \mathrm{m}^{2} \mathrm{UV}$ irradiated $\lambda$ (UV $\lambda_{20}, n=147$ ), $80 \mathrm{~J} / \mathrm{m}^{2} \mathrm{UV}$-irradiated $\lambda\left(U V \lambda_{80 \mathrm{~J}}, n=54\right)$, and $A A F$ arrays $\left(\mathrm{AAF}_{\text {array }}, n=45\right.$ ), and of truncated XPA (truncXPA) on UV $\lambda_{80 \mathrm{~J}}$ $(n=63)$. Motile particles are defined as those which moved more than $130 \mathrm{~nm}$ on DNA during $300 \mathrm{~s}$ observation. ns, no significant difference between groups by $\chi^{2}$ for all flXPA experiments, for all flXPA and truncXPA categories, or for truncXPA on UV $\lambda_{80}$ ss. flXPA on UV $\lambda_{80}$ s. $\mathbf{c}$ Example of a kymograph (cut to show only $80 \mathrm{~s}$ of the recorded movie) of motile $705 \mathrm{~nm}$ quantum dot-labeled fIXPA on ND $\lambda$. Particle position (bottom) was localized using Gaussian fittings to the intensity profile on the fluorescence image (top). Dashed lines separate phases and diffusive modes are labeled according to particle displacement: paused ( $\mathrm{P}$, displacement $<130 \mathrm{~nm}$, tan), short-range motion ( $\mathrm{S}$, displacement 130-690 nm, navy), and long-range motion ( $\mathrm{L}$, displacement $>$ $690 \mathrm{~nm}$, lavender). Arrows point to pause sites occupied by particle. $\mathbf{d}$ Stacked bar graph showing the fraction of time spent in each mode as percentage of total time recorded for all motile particles. ${ }^{\star \star \star \star} p<0.0001$ by $\chi^{2}$ for all fIXPA experiments and for truncXPA on UV $\lambda_{80 J}$ Vs. fIXPA on UV $\lambda_{80 \text { J. }}$ e Histogram of number of pause sites for fIXPA on ND $\lambda$ ( $n=31$ particles), $U V \lambda_{20 J}(n=46)$, and $U V \lambda_{80 J}(n=16)$, and for truncXPA on UV $\lambda_{80 J}(n=24)$.

DNA damage increases pausing in motile XPA particles. The proportion of seconds spent in each mode was calculated as a fraction of total recorded time for motile particles (Fig. 5d). Fulllength XPA (flXPA) demonstrated a clear dose-dependent increase in paused time with increasing damage. Motile particles of flXPA spent $52 \%$ of the time paused on ND $\lambda$ tightropes; this increased to $56 \%$ on $\mathrm{UV} \lambda_{20}, 67 \%$ on $U V \lambda_{80}$, and $71 \%$ on $\mathrm{AAF}_{\text {array }}$, and was accompanied by a decrease in time spent in the diffusive modes, especially long-range mode.

Motile XPA appeared to prefer and return to certain positions on the tightropes (Fig. 5c). These "pause sites" were defined as sites at which XPA spent at least one paused phase $(\geq 5 \mathrm{~s})$. On $\mathrm{ND} \lambda$, the majority of XPA particles $(48.4 \%)$ paused at just one position (Fig. 5e, top row). On $U V \lambda_{20}$, the majority of XPA particles $(39.1 \%)$ paused at two distinct positions (Fig. 5e, second row), and on $U V \lambda_{80}$, the majority (25.0\%) occupied 3 distinct positions, with some occupying as many as 10 positions (Fig. 5e, third row). The increasing number of pause sites observed with increasing UV lesion density in the tightropes strongly suggests that these positions correspond to UV lesions. Pause sites observed on non-damaged DNA might represent other distorted regions of the DNA (e.g., A-tract-GC junctions, spontaneous damage, or transient melting of base pairs). Due to the small sample size of motile XPA particles on $\mathrm{AAF}_{\text {array }}(n=6)$, this dataset was not included in this and subsequent analyses.

Truncated XPA exhibits reduced pausing on damaged DNA. We hypothesized that the intrinsically disordered N-terminal and Cterminal arms of XPA may play an important role during target search. We therefore examined the behavior of a truncated XPA variant (truncXPA) comprising residues M98 through T239 (ref. ${ }^{30}$ ). Truncated XPA maintains its ability to bind non-damaged $37 \mathrm{bp}$ DNA $\left(K_{\mathrm{D}}=269 \pm 22 \mathrm{nM}\right)$ with similar affinity as flXPA (Supplementary Fig. 1f). Specific binding of truncXPA to an AAF adduct $\left(K_{\mathrm{D}}=189 \pm 9 \mathrm{nM}\right)$ is $\sim 53$-fold (Supplementary Fig. $1 \mathrm{~h}$ ). Thus, we observed a reduction in specificity to dG-C8-AAF by a factor of 1.6 in the truncated XPA compared to full-length protein. All specificity was lost for CPD $\left(K_{\mathrm{D}}=269 \pm 24 \mathrm{nM}\right.$, Supplementary Fig. 1j).

On $U V \lambda_{80}$ tightropes, truncXPA exhibited the same proportion of stationary/motile and persistent/dissociated particles as flXPA (Fig. 5b). Importantly, for motile particles, we observed a 

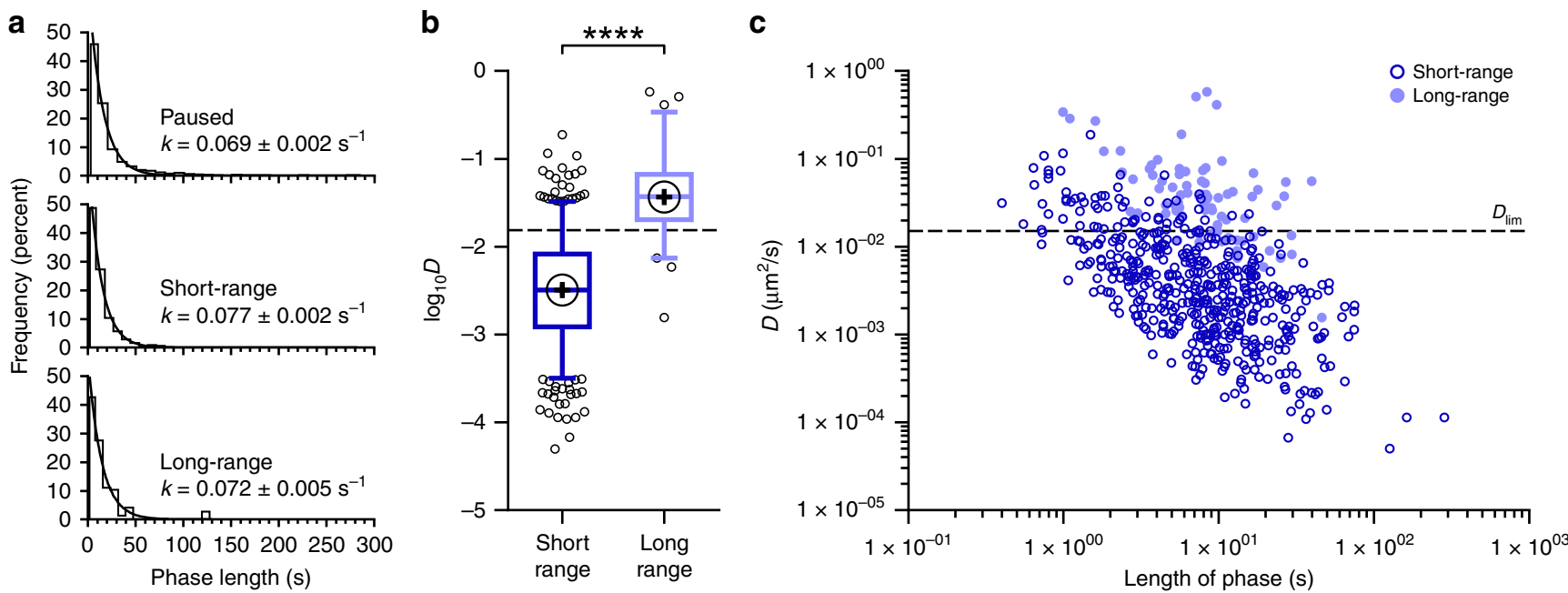

Fig. 6 Short-range motion is associated with a lower diffusion coefficient. a Cumulative frequency distributions of the lengths of paused ( $n=774$ phases), short-range ( $n=819$ phases), and long-range $\left(n=145\right.$ phases) phases for XPA on combined $\lambda$ substrates $\left(N D \lambda_{1}, U V \lambda_{20}\right.$, and UV $\lambda_{80}$ ). A single exponential is fit to each histogram and resulting $k$ is reported as best fit value \pm s.e. of the fit. Mean lifetime, $\tau=1 / k$. $\mathbf{b}$ Box and whisker plot (5-95 percentile) of the diffusion coefficient $\left(\log _{10} D\right)$ calculated for short-range $(n=505$ phases $)$ and long-range $(n=79$ phases $)$ phases of fIXPA on combined $\lambda$ substrates $\left(N D \lambda, \cup V \lambda_{20}\right.$, and $U V \lambda_{80}$ J). + , sample mean. Dashed line, $D_{\lim }$, theoretical limit to free diffusion for Qdot-flXPA. ${ }^{\star \star * *} p<0.0001$ by two-tailed Student's $t$ test. c Plot of diffusion coefficient $(D)$ vs. length of phase (same phases shown in $\mathbf{b}$ ). Dashed line, $D_{\text {lim }}$, theoretical limit to $D$ for free diffusion of Qdot-fIXPA.

significant decrease $(\sim 25 \%)$ in time spent paused and a corresponding increase in time spent undergoing long-range motion for truncXPA compared to flXPA on $U V \lambda_{80}$ (Fig. $5 \mathrm{~d}$ ). Furthermore, the number of pause sites occupied by truncXPA on $\mathrm{UV}_{\text {80J }}$ decreased dramatically (Fig. 5e). Hence, truncXPA behavior on highly damaged UV-irradiated DNA more closely resembled flXPA behavior on non-damaged DNA. These data suggest that while the core DNA-binding domain of XPA is capable of binding to damage and forming stationary complexes, its ability to transition into the paused state and form high affinity stable complexes is impaired without the $\mathrm{N}$ - and C-termini.

XPA changes search mode on the seconds time scale. We then considered the length of all individual phases to obtain an estimate for the phase lifetimes for each mode of motile XPA (fulllength and truncated). A single exponential was fit to histograms of the phase lengths (Fig. 6a). The resulting mean lifetimes $(\tau)$ are as follows: $14.4 \mathrm{~s}$ for paused phases, $13.1 \mathrm{~s}$ for short-range phases, and $14.0 \mathrm{~s}$ for long-range phases. Thus, within the defined limits of experimental temporal resolution, XPA changes its search state on the seconds time scale. Multiple comparisons of phase lengths between DNA substrates and/or protein size did not reveal any meaningful differences (Supplementary Fig. 6a). These data suggest that the time XPA molecules spend in any particular phase is not influenced by the presence of DNA damage or the disordered arms of the protein. It is also important to note that a significant proportion of XPA particles that were stationary during the entire $300 \mathrm{~s}$ observation window (Fig. 5b), may represent a distinct population of long-lived paused proteins.

Long-range motion is associated with faster diffusion rates. In order to gain insight into the rates of diffusion of motile XPA particles, we used mean squared displacement (MSD) analysis ${ }^{55}$. Because motile XPA changed its behavior so distinctly, generating MSD plots for the entire length of each kymograph was not appropriate. Instead, each diffusive phase was analyzed independently. The diffusion coefficient $(D)$ is an order of magnitude lower in the short-range mode $\left(3.2 \times 10^{-3} \mu \mathrm{m}^{2} / \mathrm{s}\right)$ compared to long-range $\left(3.7 \times 10^{-2} \mu \mathrm{m}^{2} / \mathrm{s}\right)$ (Fig. $\left.6 \mathrm{~b}\right)$. Interestingly, there is a strong correlation between phase length and diffusion coefficient, with the fastest diffusing particles spending the shortest time in that phase (Fig. 6c). Although some differences in diffusion coefficients were noted between experimental groups, we did not observe a meaningful trend (Supplementary Fig. 6b), and all plots of $D$ against phase length resulted in a similarly shaped distribution (Supplementary Fig. 6c), suggesting that diffusion rates are inherent to the mode of diffusion itself. Together, these data indicate that while XPA's entry into a paused state is dependent upon the disordered $\mathrm{N}$-terminal and C-terminal domains, phase lengths and diffusion rates are dictated by the core DBD.

The calculated theoretical limit to the diffusion coefficient for Qdot-flXPA sliding and following the helical path $\left(D_{\text {lim }}\right)$ is $0.015 \mu \mathrm{m}^{2} / \mathrm{s}$ (Supplementary Note 3 ) and appears to separate the short-range from the long-range mode (Fig. 6b, c). The fact that a significant portion of the long-range phases exceed this limit suggests that, when in this mode, XPA is undergoing an alternative mechanism of linear diffusion, namely hopping. To reconcile this, we compared the behavior of flXPA on $U V \lambda_{20 \mathrm{~J}}$ and $\mathrm{UV} \lambda_{80}$ j tightropes in buffers with different ionic strengths (Supplementary Movie 3). Proteins that are hopping along the DNA are expected to exhibit faster diffusion in higher salt concentrations, while those that are truly sliding on DNA are expected to be relatively unaffected by changes in salt ${ }^{57,58}$. Comparing the maximum displacement of XPA, we observed a significant correlation between salt concentration and range of motion (Supplementary Fig. 7a). Diffusion coefficients for XPA undergoing short-range diffusion are not affected by added salt (Supplementary Fig. 7b), thus supporting the sliding model. However, consistent with the hopping model, increased salt concentration resulted in an increase in the diffusion coefficient for XPA undergoing long-range motion.

\section{Discussion}

In this study we have pursued a collection of single molecule experiments that uniquely address several questions about how 
XPA interacts with DNA. AFM data indicate that full-length human XPA has specificity for the helix-bending dG-C8-AAF lesion embedded in a long DNA substrate and that it binds and bends both damaged and non-damaged DNA as a monomer. Single molecule fluorescence microscopy showed that XPA is primarily $(\sim 70 \%)$ stationary when bound to DNA. The motile particles exhibited episodic stalling and the presence of DNA damage increased pausing in a dose-dependent manner. A truncated XPA variant consisting of just the core DNA-binding domain (M98-T239) displayed impaired pausing compared to full-length XPA on damaged DNA tightropes. MSD analysis revealed that the long-range mode of linear diffusion had a significantly higher diffusion coefficient than the short-range mode.

Although XPA has been reported to bind DNA as a homodimer on short DNA substrates ${ }^{9}$, volumes of XPA on a 538 bp DNA substrate measured by AFM in this study are consistent with the size of a monomer, in support of previous reports ${ }^{15,21,36}$. We also observed formation of a "dimer band" at high concentrations by EMSA, but this band is indistinguishable from a complex containing one XPA bound at the lesion and one bound at the DNA end (or two otherwise distinct monomeric binding events). Indeed, our AFM data show that a significant fraction of XPA was bound to one of either ends of the DNA molecule in addition to specific sites. Previous work has addressed the issue of endbinding by performing protein-protein crosslinking experiments of Rad14 DBD on 15 or 37 bp AAF-adducted DNA ${ }^{10}$. Dimers observed in this study may be a unique property of truncated Rad14 or due to the high protein concentrations required for such experiments (mM). As such, while our current data do not exclude the possibility that two proteins may bind damaged DNA at very high concentrations, AFM imaging of full-length human XPA on long DNA substrates has allowed us to gain new insight into XPA binding stoichiometry. The monomeric state of free XPA observed at $40 \mathrm{nM}$ by AFM and up to $80 \mu \mathrm{M}$ by MALS provides further evidence against dimer formation.

The addition of a dG-C8-AAF base modification at 30\% from one end of our AFM DNA substrate resulted in increased flexibility in the DNA. Measurements of the DNA bend angle at $30 \%$ from each end of the molecule revealed two populations of angles centered $\sim 10^{\circ}$ and $\sim 35^{\circ}$, consistent with previous reports that AAF distorts B-form DNA 49,50 . Further work will be required to confirm the nature of the $10^{\circ}$ bend. XPA was shown to bend both damaged and non-damaged DNA by $\sim 60^{\circ}$, comparable to the $70^{\circ}$ DNA bend observed in the Rad14 structure ${ }^{10}$. Extensive reports in the literature suggest that XPA binds preferentially to a distorted DNA helix ${ }^{13,25}$ relative to non-damaged dsDNA, and our current work supports the hypothesis that XPA interrogates DNA by bending and testing for flexibility or pre-bent structures. The energy required to bend DNA at an AAF site is expected to be less than at a non-damaged site ${ }^{10,59}$, and thus XPA may preferentially form a stable complex more readily at this and other DNA lesions. Specificity for a bent DNA structure may be crucial for XPA to function in both damage verification, as well as its action as a scaffold protein, bound to NER intermediates. For example, XPA binds with TFIIH to bent DNA with a single-stranded overhang ${ }^{21}$.

We observed preferential XPA binding to dG-C8-AAF with a specificity factor of 660 by AFM, which is in the range of reported specificities of Taq MutS for its substrates, a T-bulge and G:T mismatch (1660 and 300, respectively $)^{38}$. XPA had a similar distribution of binding positions as we have previously observed for Rad4-Rad23 on a fluorescein-adducted substrate ${ }^{42}$. While the specificity factors determined by EMSA and AFM cannot be directly compared, in support of the AFM data, the specificity of XPA for dG-C8-AAF compared to non-damaged DNA by EMSA was $\sim 85$-fold. These levels of specificity support the "discrimination cascade" model for damage verification during
$\mathrm{NER}^{7,25,26}$. While the prevailing view has suggested that XPA is recruited after melting of DNA by TFIIH at the site of a DNA lesion, our AFM data indicate that XPA is able to detect and bind to an AAF lesion embedded in a 538 bp DNA molecule.

The role of linear diffusion in target search was explored further via the DNA tightrope assay. The episodic behavior of XPA appears to be a relatively unique property for DNA binding proteins, as few other single-particle tracking studies have yielded similar results, save for a recent report on the SA1 protein sliding on telomeric DNA tightropes ${ }^{60}$. Based on our tightrope and AFM data, it appears that monomeric XPA cycles through three distinct states on DNA: rapidly hopping over distances greater than $2 \mathrm{kbp}(690 \mathrm{~nm})$, slowly sliding over short $(<2 \mathrm{kbp})$ ranges of DNA while interrogating and bending local regions, and forming highaffinity complexes with sharply bent DNA (Fig. 7). DNA with a high propensity for bending, such as at a dG-C8-AAF adduct ${ }^{49,50}$, or $6-4 \mathrm{PP}^{54}$, promotes formation of these stable complexes. Our data indicate that switching between modes occurs stochastically on the seconds time scale, and is controlled by the core DBD. The C-terminal end of the DBD, contained within the truncXPA construct, has high levels of predicted disorder (Supplementary Fig. 1a) but can fold into an extended alpha helix ${ }^{21,33}$, suggesting possible conformational changes associated with binding modes. XPA's short-range motion is similar to the constrained diffusion we and others have observed for $\operatorname{Rad} 4^{42}, \mathrm{XPC}^{61}$, and PARP1 $1^{56}$, where the recognition protein remains in close proximity to the target site while making room for subsequent proteins to assemble. Thus, short-range diffusion by XPA may facilitate damage verification during the transition between initial damage recognition during NER and XPA's scaffolding function.

The paused and diffusive states exhibited by motile XPA molecules are reminiscent of the two-state model proposed by Slutsky and Mirny ${ }^{62}$. In response to the speed-stability paradox of protein-DNA target search, the authors suggest that proteins adopt two conformations: a search state with a smooth DNAbinding energy landscape $\left(\sigma \lesssim 1-2 \times k_{\mathrm{B}} T\right)$, allowing for rapid search, and a recognition state with a rugged energy landscape $(\sigma$ $\left.\gtrsim 5 \times k_{\mathrm{B}} T\right)^{62,63}$. Linear diffusion observed for XPA fits this model. Paused particles conform to a recognition state while short-range and long-range diffusing particles correspond to distinct subgroups (and thus distinct energy landscapes) within a search state.

The energy barrier to free diffusion $\left(\sigma=1.6 \times k_{\mathrm{B}} T\right.$, Supplementary Note 3 ) in the short-range mode (i.e., displacement less than $690 \mathrm{~nm}$ or $\sim 2 \mathrm{kbp}$ ) is essentially the same as $\operatorname{Rad} 4$-Rad23 undergoing constrained motion ${ }^{42}$. We attribute the slower rate of diffusion observed in the short-range mode to two factors. First, as XPA bends DNA to assess damage/helical distortions, this likely induces propagation of the bend along the DNA molecule, thereby increasing the roughness of the energy landscape and ultimately limiting diffusion ${ }^{64}$. Second, XPA is translocating along the DNA by spiraling in constant contact with the helix.

Diffusion coefficients determined for XPA in the long-range mode, however, were affected by the ionic strength of the buffer and exceeded $D_{\lim }$ for XPA sliding in this manner (and consequently, we are unable to calculate corresponding energy barriers to diffusion). Therefore, it is possible that XPA is hopping (i.e., rapidly undergoing micro-associations and dissociations from the DNA) in order to achieve the faster diffusion observed. In the cell, a search mechanism involving hopping would have the advantage of the protein being able to move along the DNA without being stopped by other protein-DNA complexes or nucleosomes.

Truncated XPA, consisting of residues 98-239 of the core DNA-binding domain, maintains its ability to adopt a recognition state on damaged DNA. However, motile particles of truncXPA were significantly impaired in their ability to pause on damaged DNA, as demonstrated by a decreased number of pause sites and 


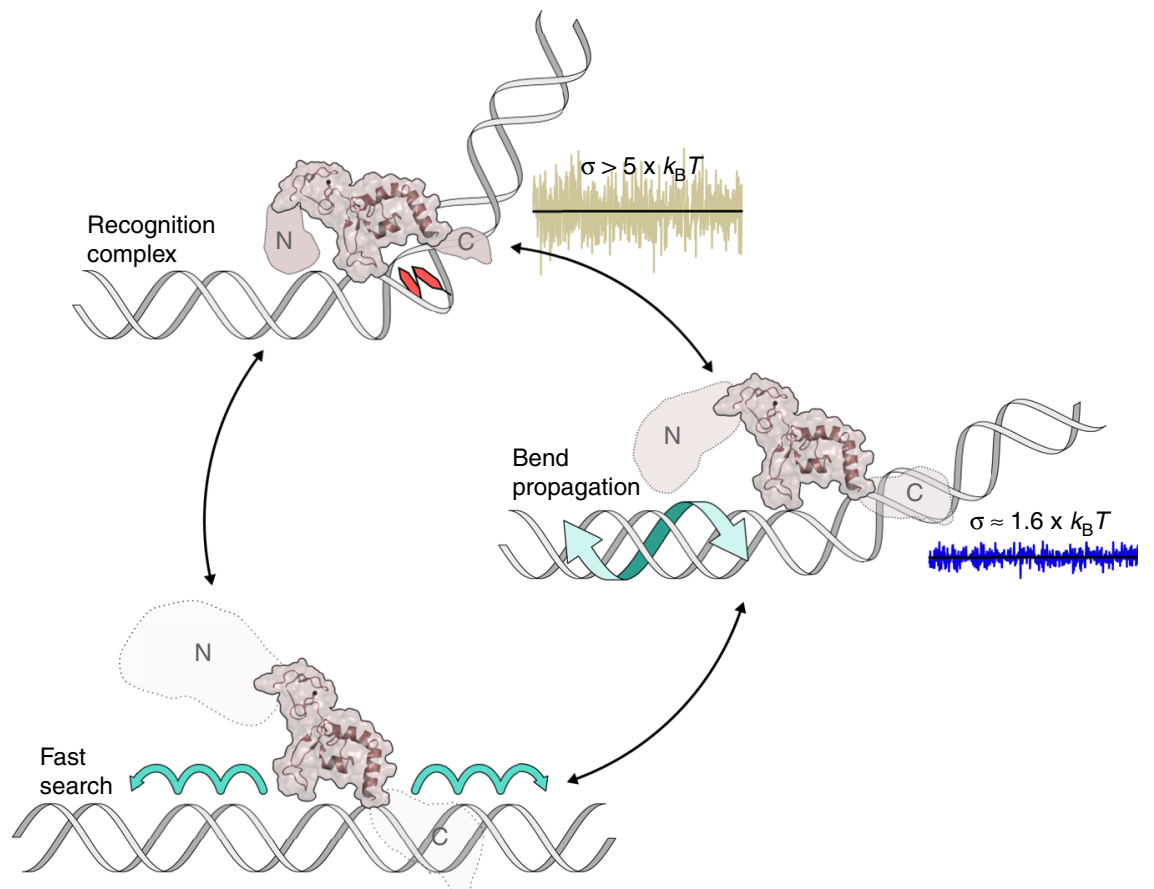

Fig. 7 Working model of XPA linear diffusion on DNA. Fast search (long-range linear diffusion): monomeric XPA translocates rapidly by hopping (microassociations/dissociations) along the DNA backbone. The protein's disorder and lack of contacts with DNA permit rapid diffusion $\left(D \approx 0.04 \mu \mathrm{m}^{2} / \mathrm{s}\right)$. Bend propagation (short-range linear diffusion): XPA follows the path of the major or minor groove, spiraling along $D N A\left(D \approx 0.003 \mu m^{2} / \mathrm{s}\right)$. The $N-$ and $C$ termini of the protein may be partially folded, making more contacts with the DNA. The protein bends DNA, testing for flexibility/aberrations, and propagation of the bend further slows diffusion. Recognition complex (paused and stationary particles): the disordered ends of the protein fold into a stable complex, bending the DNA $\sim 60^{\circ}$. The NMR structure of the XPA DNA-binding domain (PDB 1XPA) was used in combination with an estimation for the Nand C-termini (disorder represented by size/transparency) as an approximate model to display the complete XPA molecule.

a decreased total time spent in the paused mode. Compared to flXPA, truncXPA had approximately half the specificity for AAFadducted DNA, and displayed no specificity for CPD-containing DNA. We therefore suggest that the N-terminal and C-terminal arms likely play a significant role in helping to identify alterations in the DNA helix and may serve as metaphorical brakes, allowing XPA to slow its search and test the site for a lesion or help in recruiting other repair factors. These data are consistent with a model in which the core DNA-binding domain is able to form stable complexes, but the disordered arms play a role in embracing the DNA and interrogating for helix-distorting damage, inducing a conformational change in both the protein and DNA to initiate pausing (Fig. 7). As NER proceeds and XPA plays a major role as a scaffold protein, the arms could then be available to interact with other DNA repair proteins. This is supported by published interactions of RPA32, ERCC1, and TFIIH (XPD) with the disordered N-terminus of XPA, as well as TFIIH (p52 and p8/ TTDA) with the XPA C-terminus ${ }^{21,23}$. Given the many reported interactions between XPA and other NER proteins ${ }^{23}$, XPA may show altered dynamics on DNA in the presence of other repair partners. Thus, we present our model as an important starting point, illustrating XPA-DNA binding behavior and diffusive properties in isolation.

\section{Methods}

Protein purification. His-flXPA. Full-length, wild-type human XPA cDNA was cloned into the pIBA35 vector with an N-terminal His tag. The plasmid was transformed into One Shot BL21(DE3)pLysS competent E. coli cells (Invitrogen). Cultures were grown in LB medium containing $100 \mu \mathrm{g} / \mathrm{ml}$ ampicillin and $34 \mu \mathrm{g} / \mathrm{ml}$ chloramphenicol at $37^{\circ} \mathrm{C}$ until the $\mathrm{OD}_{600}$ reached $\sim 0.6$. At this point, expression was induced with $0.5 \mathrm{mM}$ IPTG and $10 \mu \mathrm{M} \mathrm{ZnCl}_{2}$ and cultures continued to grow for $4 \mathrm{~h}$. Cells were harvested by centrifugation at $16,000 \times g$ for $8 \mathrm{~min}$ at $4{ }^{\circ} \mathrm{C}$. All the following purification steps were performed on ice or at $4{ }^{\circ} \mathrm{C}$. Cell pellets were resuspended in His-XPA lysis buffer $(25 \mathrm{mM}$ Tris- $\mathrm{HCl}, \mathrm{pH} 7.5,100 \mathrm{mM} \mathrm{NaCl}, 5$
mM DTT, $10 \%$ (v/v) glycerol, $10 \mu \mathrm{M} \mathrm{ZnCl}_{2}$, and $30 \mathrm{mM}$ imidazole), lysed by sonication, and the insoluble fraction was pelleted by centrifugation at $45,000 \times g$ for $45 \mathrm{~min}$. The supernatant was loaded onto an equilibrated HisTrap HP nickel column (GE) and washed with 30 column volumes (CV) of His buffer A (25 mM Tris- $\mathrm{HCl}, \mathrm{pH} 7.5,100 \mathrm{mM} \mathrm{NaCl}, 5 \mathrm{mM}$ DTT, $10 \%$ glycerol, $10 \mu \mathrm{M} \mathrm{ZnCl}$, and 30 $\mathrm{mM}$ imidazole). The sample was eluted with a gradient of $0-100 \%$ in $10 \mathrm{CV}$, His buffer A to His buffer B (25 mM Tris- $\mathrm{HCl} \mathrm{pH} \mathrm{7.5,100} \mathrm{mM} \mathrm{NaCl,} 5 \mathrm{mM}$ DTT, $10 \%$ glycerol, $10 \mu \mathrm{M} \mathrm{ZnCl}$, and $500 \mathrm{mM}$ imidazole). Fractions containing XPA were pooled and loaded onto an equilibrated MonoQ column and washed with $5 \mathrm{CV}$ MonoQ buffer A ( $25 \mathrm{mM}$ Tris- $\mathrm{HCl}, \mathrm{pH} 7.5,50 \mathrm{mM} \mathrm{NaCl}, 5 \mathrm{mM}$ DTT, $10 \%$ glycerol, and $10 \mu \mathrm{M} \mathrm{ZnCl}_{2}$ ). XPA was eluted with a gradient of $0-100 \%$ in $15 \mathrm{CV}$ MonoQ buffer A to MonoQ buffer B (25 mM Tris- $\mathrm{HCl}, \mathrm{pH} 7.5,1 \mathrm{M} \mathrm{NaCl}, 5 \mathrm{mM}$ DTT, $10 \%$ glycerol, and $10 \mu \mathrm{M} \mathrm{ZnCl}_{2}$ ). Fractions containing XPA were pooled, diluted with MonoQ buffer A, loaded onto an equilibrated Heparin column, and washed with 5 CV MonoQ buffer A. XPA was eluted with a gradient of $0-100 \%$ in 35 CV MonoQ buffer A to MonoQ buffer B. Fractions containing XPA were pooled and loaded onto a size exclusion column (HiLoad 16/60 Superdex 200), which was equilibrated with the His-XPA SEC buffer (50 mM HEPES, pH 8.0, 150 $\mathrm{mM} \mathrm{NaCl}, 5 \mathrm{mM} \mathrm{MgCl} 2,5 \mathrm{mM}$ DTT, 5\% glycerol, and $10 \mu \mathrm{M} \mathrm{ZnCl}_{2}$ ). XPA eluted as a single peak and peak fractions were pooled, aliquoted, and flash frozen in liquid nitrogen and stored at $-80^{\circ} \mathrm{C}$.

His-flXPA-StrepII and His-truncXPA-StrepII. Full-length, wild-type human XPA cDNA was cloned into the pIBA43 vector with an N-terminal His tag and Cterminal StrepII tag. To make truncated XPA, the N- and C-termini were deleted from this plasmid (cloning by Gene Universal), leaving only residues 98-239. Both constructs were expressed and purified as described below.

The plasmid was transformed into One Shot BL21(DE3)pLysS competent E. coli cells (Invitrogen). Cultures were grown in LB medium containing $100 \mu \mathrm{g} / \mathrm{ml}$ ampicillin, $34 \mu \mathrm{g} / \mathrm{ml}$ chloramphenicol, and $10 \mu \mathrm{M} \mathrm{ZnCl}_{2}$ at $37^{\circ} \mathrm{C}$ until the $\mathrm{OD}_{600}$ reached $\sim 0.4$. The temperature was then decreased to $16^{\circ} \mathrm{C}$ and growth was continued until an $\mathrm{OD}_{600}$ of $\sim 0.6$ was achieved. At this point, expression was induced with $0.2 \mathrm{mM}$ IPTG and cultures continued to grow overnight. Cells were harvested by centrifugation at $5000 \times \mathrm{g}$ for $30 \mathrm{~min}$ at $4^{\circ} \mathrm{C}$. All the following purification steps were performed on ice or at $4{ }^{\circ} \mathrm{C}$ and, between each step, samples were analyzed on $4-12 \%$ Bis-Tris SDS gels and stained with SimplyBlue SafeStain (Invitrogen). Cell pellets were resuspended in His-XPA-StrepII lysis buffer $(50 \mathrm{mM}$ potassium phosphate, $\mathrm{pH} 7.9,200 \mathrm{mM} \mathrm{KCl}, 20 \mathrm{mM}$ imidazole, $5 \%$ glycerol, $0.02 \%$ sodium azide, and EDTA-free Protease inhibitor cocktail), lysed by sonication, and the insoluble fraction was pelleted by ultracentrifugation at $147,000 \times g$ for $2 \mathrm{~h}$. The supernatant was loaded onto an equilibrated HisTrap HP nickel column (GE) and 
washed with $30 \mathrm{CV}$ His buffer $\mathrm{C}\left(3.5 \mathrm{mM} \mathrm{KH}_{2} \mathrm{PO}_{4}, 46.5 \mathrm{mM} \mathrm{K}_{2} \mathrm{HPO}_{4}, 200 \mathrm{mM}\right.$ $\mathrm{KCl}, 20 \mathrm{mM}$ imidazole, $5 \%$ glycerol, and $0.02 \%$ sodium azide). The sample was eluted with a gradient of $0-50 \%$ His buffer $\mathrm{C}$ to His buffer $\mathrm{D}\left(3.5 \mathrm{mM} \mathrm{KH}_{2} \mathrm{PO}_{4}\right.$, $46.5 \mathrm{mM} \mathrm{K}_{2} \mathrm{HPO}_{4}, 200 \mathrm{mM} \mathrm{KCl}, 500 \mathrm{mM}$ imidazole, $5 \%$ glycerol, and $0.02 \%$ sodium azide). Fractions containing XPA were pooled and loaded onto an equilibrated StrepTrap HP column with StrepTactin sepharose (GE) and washed with 50 column volumes Strep buffer A $(50 \mathrm{mM}$ Tris- $\mathrm{HCl}, \mathrm{pH} 8.0,200 \mathrm{mM} \mathrm{KCl}$, and $0.02 \%$ sodium azide) and eluted with Strep buffer B (50 mM Tris-HCl, $\mathrm{pH} 8.0$, $200 \mathrm{mM} \mathrm{KCl}, 5 \mathrm{mM}$ desthiobiotin, and $0.02 \%$ sodium azide). Fractions containing XPA were pooled and dialyzed into His-XPA-StrepII SEC buffer $(50 \mathrm{mM}$ HEPES, $\mathrm{pH} 8.0,200 \mathrm{mM} \mathrm{KCl}, 5 \mathrm{mM} \mathrm{MgCl} 2,5 \mathrm{mM} \mathrm{DTT}, 10 \%$ glycerol, and $0.02 \%$ sodium azide). Size exclusion chromatography was performed using the AKTA FPLC with a HiLoad 16/60 Superdex 200 column (Amersham). XPA eluted as a single peak and peak fractions were pooled, aliquoted, and flash frozen in liquid nitrogen and stored at $-80{ }^{\circ} \mathrm{C}$. His-XPA-StrepII and His-XPA were compared by EMSA and AFM to confirm that the addition of the StrepII tag did not affect protein behavior.

His-flXPA was used in all AFM experiments and some DNA tightrope experiments. His-flXPA-StrepII was used for all electrophoretic mobility shift assays, multiangle light scattering, and some DNA tightrope experiments. To verify that both protein preparations exhibited similar behavior, they were compared by $\mathrm{AFM}$ with respect to the following parameters: binding position on $\mathrm{AAF}_{538}$, induced DNA bend angle, and AFM volume (Supplementary Fig. 5a-d). Because His-flXPA-StrepII has a slightly higher molecular weight than His-flXPA, HisflXPA-StrepII results were only used for validation and were not combined with His-flXPA results for AFM experiments. Since both preparations behaved similarly in our AFM studies, we combined the data obtained in the DNA tightrope experiments.

Multiangle light scattering. Multiangle light scattering combined with size exclusion chromatography (SEC-MALS) was used to determine the oligomeric state of purified His-flXPA-StrepII in solution, as previously described ${ }^{65,66}$. Briefly, $100 \mu \mathrm{L}$ of His-flXPA-StrepII at concentrations of $65 \mu \mathrm{M}$ or $80 \mu \mathrm{M}$ were injected on a Superdex 200 10/300 column (GE Healthcare) pre-equilibrated with XPA MALS buffer ( $50 \mathrm{mM}$ HEPES, $\mathrm{pH} 8.0,200 \mathrm{mM} \mathrm{KCl}, 5 \mathrm{mM} \mathrm{MgCl}_{2}, 5 \mathrm{mM}$ DTT, and $10 \%$ glycerol) and eluted at a constant flow rate of $0.5 \mathrm{ml} / \mathrm{min}$ at room temperature. The molecular mass of the eluting sample was determined using the light scattering signal from a Dawn Heleos 8+ detector and the concentration signal from an Optilab T-rEX refractive index detector (both Wyatt Technologies). Data analysis was carried out with the ASTRA software (version 6.1.5.22, Wyatt Technologies).

DNA substrate preparation. $A A F_{37}$ oligo. The $37 \mathrm{nt}$ oligonucleotide containing one dG-C8-AAF lesion $\left(\mathrm{AAF}_{37}\right.$-top, sequence below) was prepared as published ${ }^{10}$. Briefly, the synthesis was performed on an ABI 394 Nucleic Acid Synthesis System (Life Technologies) using ultra-mild conditions and commercially available phosphoramidites from Glen Research and Link Technologies. The AAF lesion was introduced with the help of a dG-AAF phosphoramidite with an isopropylphenoxyacetyl protecting group at the $\mathrm{N}^{2}$-position ${ }^{10}$. The coupling time of the dG-AAF phosphoramidite was extended to $2 \times 10 \mathrm{~min}$ to achieve good coupling yields. The crude oligonucleotide was deprotected using the reported ultramild conditions and purified by reverse phase high-performance liquid chromatography. Final desalting was performed with a Sep-PAK cartridge (Waters).

37 bp DNA duplexes for EMSA. Oligonucleotide sequences ( $\mathrm{G}^{\mathrm{AAF}}=\mathrm{dG}-\mathrm{C} 8-\mathrm{AAF}$; $\mathrm{T}<>\mathrm{T}=\mathrm{CPD} ; 6 \mathrm{FAM}=$ fluorescein; all purchased from IDT except $\mathrm{AAF}_{37}$-top):

$\mathrm{ND}_{37}$-top: 5'-phosphate-CCGAGTCATTCCTGCAGCGAGTCCATGGGAGT CAAAT

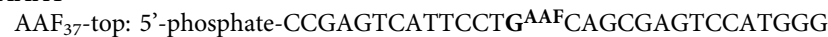
AGTCAAAT

CPD $_{37}$-top: 5'-phosphate-CCGAGTCATTCCTGCAGCGAT $<>$ TCCATGGG AGTCAAAT

FAM $_{37}$-bottom: 5'-6FAM-ATTTGACTCCCATGGACTCGCTGCAGGAATG ACTCGG

$\mathrm{CPD}_{37}$-bottom: 5'-6FAM- ATTTGACTCCCATGGAATCGCTGCAGGAAT GACTCGG

$\mathrm{ND}_{37}$ was prepared by annealing $\mathrm{ND}_{37}$-top and $\mathrm{FAM}_{37}$-bottom. $\mathrm{AAF}_{37}$ was prepared by annealing $\mathrm{AAF}_{37}$-top and $\mathrm{FAM}_{37}$-bottom. $\mathrm{CPD}_{37}$ was prepared by annealing $\mathrm{CPD}_{37}$-top and $\mathrm{CPD}_{37}$-bottom. Annealing reactions contained $1.25 \mu \mathrm{M}$ top strand, $1 \mu \mathrm{M}$ bottom strand, $10 \mathrm{mM}$ Tris- $\mathrm{HCl}, \mathrm{pH} 8.0$, and $100 \mathrm{mM} \mathrm{KCl}$. Reactions were incubated at $95^{\circ} \mathrm{C}$ for 5 min then cooled slowly to room temperature.

Defined lesion plasmids. Plasmids containing single site-specific dG-C8-AAF adducts were prepared as described previously ${ }^{53,55}$. Briefly, purified pSCW01 plasmids were nicked by Nt.BstNBI to create a 37-base gap. A 37mer containing a single dG-C8-AAF ( $\mathrm{AAF}_{37}$-top, above) was annealed into this gap and the backbone was sealed with T4 DNA ligase.

DNA duplexes for AFM. Substrates for AFM were prepared as described previously $y^{55}$. Essentially, a 538 bp DNA fragment was cut out of either unmodified pSCW01 plasmid (for $\mathrm{ND}_{538}$ ) or pSCW01 with a site-specific dG-C8-AAF lesion, described above (for $\mathrm{AAF}_{538}$ ). The plasmid was incubated with restriction enzymes $\mathrm{XmnI}$ and PciI, cutting 372 bp 5' to and 165 bp 3' to the lesion, respectively. Nick ${ }_{514}$ was prepared by amplifying a 514 bp fragment from the pSCW01 plasmid and treating with Nt.BspQI to create a nick at $36 \%$ of the DNA contour length.

Long DNA substrates for tightrope assay. The ND $\lambda$ substrate was prepared by diluting $\lambda$ genomic DNA (NEB) to $50 \mathrm{ng} / \mu \mathrm{l}$ in $10 \mathrm{mM}$ Tris-HCl, $\mathrm{pH}$ 8.5. The $\mathrm{UV}_{20}$ substrate was prepared by treating ND $\lambda$ with $20 \mathrm{~J} / \mathrm{m}^{2}$ of UV-C radiation $(254 \mathrm{~nm})$. A qPCR assay was performed previously to confirm the presence of UV photoproducts (6-4 PPs and CPDs) at a density of $\sim 1$ lesion per $2.2 \mathrm{kbp}$ (ref. ${ }^{53}$ ). To prepare $\mathrm{UV} \lambda_{80}$ and increase the lesion density such that there was $\sim 1$ lesion per 550 bp (i.e., $16-4 \mathrm{PP}$ every $2.2 \mathrm{kbp}$ ), ND $\lambda$ was treated with $80 \mathrm{~J} / \mathrm{m}^{2}$ of UV-C. The dG-C8-AAF arrays were prepared as described previously $y^{53,55}$, using the defined lesion plasmid described above. Lesion-containing pSCW01 was linearized via restriction digest by XhoI (NEB) then incubated with T4 DNA ligase (NEB) to achieve long ( $>40 \mathrm{kbp})$ tandemly ligated products with one dG-C8-AAF every $2 \mathrm{kbp}$.

Electrophoretic mobility shift assay (EMSA). XPA-DNA reactions were prepared by combining $8 \mathrm{nM} 37$ bp DNA with varying amounts of His-flXPA-StrepI in XPA EMSA buffer (20 mM HEPES, pH 7.5, $150 \mathrm{mM} \mathrm{NaCl}, 5 \mathrm{mM}$ DTT, $0.5 \mathrm{mg} / \mathrm{ml}$ $\mathrm{BSA}$, and $5 \%$ glycerol) in a final reaction volume of $10 \mu \mathrm{l}$. Each reaction was incubated for $25 \mathrm{~min}$ at room temperature then immediately loaded on two pre-run 5\% non-denaturing polyacrylamide gels (37.5:1 acrylamide:bis). Both pre-run and run were performed at $4^{\circ} \mathrm{C}$, in $0.5 \times$ TBE buffer $(44.5 \mathrm{mM}$ Tris, $44.5 \mathrm{mM}$ boric acid, $1 \mathrm{mM}$ EDTA, $\mathrm{pH} 8.4$ ), at constant voltage ( $90 \mathrm{~V})$. DNA bands were visualized using a laser scanner for fluorescence (Typhoon, Amersham).

Gel images were quantified by measuring signal intensities of each band (ImageJ, NIH). The percentage of DNA bound was determined by dividing the intensity of the shifted ("bound") DNA by the sum of all bands in a lane. These values were plotted against XPA concentration and the data were fit to the following equation via nonlinear regression (GraphPad Prism):

$$
\begin{aligned}
& \% \text { DNA Bound }=100 \\
& \times \frac{\left(P+D+K_{\mathrm{D}}\right)-\sqrt{\left(P+D+K_{\mathrm{D}}\right)^{2}-4 P D}}{2 D}
\end{aligned}
$$

where $K_{\mathrm{D}}$ is the equilibrium dissociation constant, $P$ is the total protein concentration, and $D$ is the total DNA concentration. This model was chosen because our experimental conditions required that the DNA concentration be in the same molar range as the $K_{\mathrm{D}}\left(\right.$ ref. $\left.{ }^{67}\right)$.

Atomic force microscopy (AFM). Sample preparation. Samples for AFM were prepared as previously described ${ }^{55}$. All buffers and solutions were first filtered through $0.02 \mu \mathrm{m}$ sterile filters (Whatman). For imaging of free proteins or free DNA (i.e., no reaction), the sample was diluted to either $40 \mathrm{nM}$ (protein) or 4 nM (DNA) in AFM deposition buffer (25 mM HEPES, pH 7.5, $25 \mathrm{mM} \mathrm{NaOAc}$ and $\left.10 \mathrm{mM} \mathrm{Mg}(\mathrm{OAc})_{2}\right)$ which had been pre-warmed to $65^{\circ} \mathrm{C}$ and brought back to room temperature. XPA-DNA reactions consisted of $100 \mathrm{nM} 538 \mathrm{bp}$ DNA $\left(\mathrm{ND}_{538}\right.$ or $\left.\mathrm{AAF}_{538}\right)$ and $0.6-4 \mu \mathrm{M}$ His-flXPA in XPA AFM buffer $(50 \mathrm{mM}$ HEPES, pH 8.0, $150 \mathrm{mM} \mathrm{NaCl}, 5 \mathrm{mM} \mathrm{MgCl}_{2}, 10 \mu \mathrm{M} \mathrm{ZnCl}_{2}, 5 \mathrm{mM}$ DTT, and $5 \%$ glycerol) in a total volume of $10 \mu \mathrm{l}$. APE1-DNA and Pol $\beta$-DNA reactions consisted of $100 \mathrm{nM} 514 \mathrm{bp}$ DNA ( Nick $_{514}$ ) and $500 \mathrm{nM}$ protein in APE1 buffer (50 $\mathrm{mM}$ HEPES, pH 7.5, $150 \mathrm{mM} \mathrm{NaCl}, 10 \mathrm{mM} \mathrm{MgCl}_{2}$ ) in a total volume of $10 \mu \mathrm{l}$. Each binding reaction was incubated for $30 \mathrm{~min}$ at room temperature then diluted 1:25 in AFM deposition buffer. Twenty five microliter droplets were deposited on freshly cleaved mica, allowed to equilibrate for $30 \mathrm{~s}$ with gentle rocking, then washed with $1 \mathrm{ml}$ of filtered $\mathrm{H}_{2} \mathrm{O}$ and dried under a gentle stream of nitrogen gas.

Data collection. All AFM images were obtained using ScanAsyst PeakForce Tapping mode in air on a Multimode V Microscope with an E scanner (Bruker). Samples were scanned with a triangular tip with a nominal radius of $2 \mathrm{~nm}$, mounted on a silicon nitride cantilever (SCANASYST-AIR, Bruker). Probes were replaced for each new experiment or more frequently as needed. $1 \times 1$ micron images were collected at a resolution of $512 \times 512$ pixels and a scan rate of 0.977 $\mathrm{Hz}$. The peak force setpoint was $0.01988 \mathrm{~V}$.

Data analysis: free protein standard. To generate the standard curve relating AFM volumes to molecular weight, analysis was performed on AFM images with the isolated protein samples. The following proteins of known MW were used: recombinant human HMGB1 (Abcam), His-tagged human APE1 (gift from Sam Wilson), His-tagged human DNA polymerase $\beta$ (gift from Sam Wilson), and Histagged UvrD (purified as published ${ }^{68}$ ). Particle dimensions were measured using Image SXM software and used to calculate volumes:

$$
V=A \times(H-B)
$$

where $V$ is the particle volume, $A$ is the area of the particle footprint (determined via a set density threshold above background noise), $H$ is the mean height of the particle, and $B$ is the background height of the overall image ${ }^{69}$.

Data analysis: intrinsic DNA bend angle. To determine the intrinsic bend angles of DNA substrates at 30\% from each end, AFM images containing only the DNA were analyzed. DNA molecules used in this analysis had to be completely visible and isolated (i.e., not continuing past the edge of the image nor overlapping with itself or another molecule) and the total contour length must be within the range of $\pm 10 \%$ of the expected length. Measurements were done on TIF images using 
ImageJ software (NIH). The total DNA contour length was first measured and points at 30\% from both ends were marked. Local bend angles at these sites were measured and are reported as the supplementary angle, $\theta$ (Fig. 4).

Data analysis: protein-DNA complexes. In addition to the criteria for usable DNA molecules as described above, the analysis of protein-DNA complexes first required the identification of bound proteins using the following criteria: (a) the height of the complex must be greater than the average height of the DNA molecule and (b) the complex width must be greater than the average width of the DNA molecule.

Methods for measuring protein binding position and induced DNA bend angle using Image software (NIH) have been described in detail ${ }^{55}$. Briefly, binding position was determined by dividing the contour length of the DNA molecule from the center of a bound protein to the closest DNA end by the total DNA contour length. XPA-induced DNA bend angles were measured at sites of bound XPA. In cases where two or more proteins were bound to the same DNA molecule, angles were not measured.

To measure protein volume when bound to DNA, the DNA volume was estimated and subtracted from the total complex volume (Supplementary Fig. 4A). Image SXM software was used to trace the perimeter of the complex. The length of the DNA through this space was projected assuming that the DNA runs through the center of the complex. Then, two unbound regions of DNA on either side of the complex, with lengths corresponding to that of the complex, were delineated. In cases where the protein was bound near the end of the DNA or near another protein, two unbound regions of DNA were chosen at other available locations on the same molecule. Volumes of all three regions (complex, DNA1, and DNA2) were determined as described above (Equation 2). Protein volume was determined as the total complex volume minus the average of the two unbound DNA volumes:

$$
V_{\text {protein }}=V_{\text {complex }}-\frac{V_{\mathrm{DNA} 1}+V_{\mathrm{DNA} 2}}{2}
$$

Histograms of all AFM results were plotted and Gaussians were fit to the data by nonlinear regression in GraphPad Prism. The number of histogram bins corresponds to the square root of the sample size.

DNA tightrope assay. Flow cell set-up. All steps for reagent/material preparation, flow cell set-up, protein labeling, imaging, and data analysis for the tightrope assay have been described in detail ${ }^{55}$ according to methods developed previously ${ }^{51,52}$. Briefly, flow cells were prepared by attaching slides with inlet/outlet tubing to PEGylated coverslips via tape spacers. Flow cells were incubated in blocking buffer (10 mM HEPES, pH 7.5, $50 \mathrm{mM} \mathrm{NaCl}$, and $1 \mathrm{mg} / \mathrm{ml} \mathrm{BSA}$ ) for $10 \mathrm{~min}$, then poly-Llysine coated silica microspheres ( $5 \mu \mathrm{m}$ diameter) were flowed in and dispersed across the coverslip. Long DNA substrates were suspended between beads using continuous hydrodynamic flow with alternating direction in tightrope buffer (20 mM HEPES, $\mathrm{pH} 7.5,50 \mathrm{mM} \mathrm{NaCl}, 3 \mathrm{mM} \mathrm{MgCl}$ ).

Protein labeling. His-flXPA, His-flXPA-StrepII, or His-truncXPA-StrepII was labeled with either $705 \mathrm{~nm}$ or $605 \mathrm{~nm}$ quantum dots (Qdots). The former strategy was accomplished by first incubating streptavidin-coated 705 Qdot (Invitrogen) with biotinylated anti-His antibody, at a final concentration of $167 \mathrm{nM}$ Qdot and $833 \mathrm{nM}$ antibody. Then, this mixture was incubated with an equal volume of $167 \mathrm{nM} \mathrm{XPA}$; the final XPA concentration was $83.3 \mathrm{nM}$. The latter strategy was accomplished by first incubating XPA with a mouse monoclonal anti-His antibody, both at a final concentration of $200 \mathrm{nM}$. Then, this mixture was incubated with an equal volume of $1 \mu \mathrm{M} 605$ Qdot conjugated to an anti-mouse secondary antibody (Invitrogen); final XPA concentration was $100 \mathrm{nM}$. Labeled protein mixtures were diluted 4:100 in XPA tightrope buffer ( $25 \mathrm{mM}$ HEPES, pH 8.3, $100 \mathrm{mM} \mathrm{KCl}, 1 \mathrm{mM} \mathrm{EDTA}, 0.55 \mathrm{mg} / \mathrm{ml}$ BSA, 1 mM DTT, and 10\% glycerol). The final XPA concentration in the flow cell was 3-4 nM. To check for background binding by the Qdots or antibodies, controls were performed using the above conjugations with buffer instead of XPA. To verify that the two different Qdot labeling strategies did not impact results, the behavior of XPA labeled with either the 605 Qdot or 705 Qdot was compared on $U V \lambda_{20 J}$ tightropes, showing no significant difference (Supplementary Fig. 5e).

For $150 \mathrm{mM} \mathrm{NaCl}$ experiments, $150 \mathrm{mM} \mathrm{NaCl}$ buffer (25 mM HEPES, pH 7.5, $150 \mathrm{mM} \mathrm{NaCl}, 1 \mathrm{mM}$ DTT, and $0.1 \mathrm{mg} / \mathrm{ml} \mathrm{BSA}$ ) was used in place of XPA tightrope buffer. For $1 \mathrm{M} \mathrm{NaCl}$ experiments, stationary particles of XPA were recorded in XPA tightrope buffer and, during recording, the buffer in the flow cell was replaced with $1 \mathrm{M} \mathrm{NaCl}$ buffer ( $1 \mathrm{M} \mathrm{NaCl}, 20 \mathrm{mM}$ HEPES, pH 8.3, $80 \mathrm{mM}$ $\mathrm{KCl}, 0.8 \mathrm{mM}$ EDTA, and $8 \%$ glycerol), taking $\sim 40 \mathrm{~s}$ of flow.

Data collection. Movies of XPA-DNA interactions were recorded on an inverted fluorescence microscope (Nikon Ti) with an 100X oil-based high-NA objective for TIRF-M and a high-speed sCMOS camera (Andor and Teledyne Photometrics). Qdots were excited with a $488 \mathrm{~nm}$ laser at an optimal oblique (sub-TIRF) angle and visualized without an emission filter. Movies were taken for 5 min with frame rates between $\sim 10$ and $\sim 12.5$ fps.

Data analysis. Movie files were converted to a time series of individual TIF files (NIS-Elements, Nikon) and imported into ImageJ (NIH). Kymographs were generated using the slice function over the trajectory of the particle along the DNA. These were processed by FFT bandpass filtering to reduce noise (filter range 3-40 pixels, with suppression of vertical stripes). A Gaussian Fit plugin was used to fit the fluorescence intensity in the kymograph to a one-dimensional Gaussian at each point along the $x$-axis (i.e., each frame or time point ${ }^{51}$. Fitting data was processed using custom scripts in MATLAB (MathWorks) to exclude poorly fitted positions and convert particle position from pixels to $\mathrm{nm}$.

First, each particle (i.e., one kymograph, 5 min observation) was categorized based on whether it moved at all during the observation window (stationary vs. motile) and whether it dissociated during recording (persistent vs. dissociated). Dissociation was defined as the disappearance of Qdot-XPA for at least 200 frames $(\sim 20 \mathrm{~s})$. We have previously reported that the mean positional accuracy for a 605 $\mathrm{nm}$ Qdot bound to biotin is $6 \pm 3 \mathrm{~nm}$ by Gaussian fitting of the fluorescence intensity to a point spread function ${ }^{53}$. The position uncertainty over time has been determined to be $36 \pm 3 \mathrm{~nm}(\sim 100 \mathrm{bp})$, accounting for stage drift, DNA movement, and thermal fluctuation $s^{53}$. We used a conservative cutoff of $130 \mathrm{~nm}$ (three pixels, $\sim 400 \mathrm{bp}$ ) to classify motile particles ${ }^{42,56}$.

Motile particles were analyzed further for different modes of diffusion. Each kymograph was broken down into phases, falling into three possible modes of behavior: paused (particle displacement not varying more than $130 \mathrm{~nm}$ ), short-range diffusion (displacement between $130 \mathrm{~nm}$ and $690 \mathrm{~nm}$ ), and long-range diffusion (displacement greater than $690 \mathrm{~nm}$ ). Shorter range modes were only allowed to interrupt longer range modes if they persisted for at least $5 \mathrm{~s}$. For example, if a particle was exhibiting short-range behavior, paused (i.e., stationary) for $10 \mathrm{~s}$, then went back to short-range behavior, this would be counted as three phases; if the pause only lasted $2 \mathrm{~s}$, this would be counted as a single short-range phase. If a particle was paused prior to recording, the first phase of a kymograph may be less than $5 \mathrm{~s}$. Each motile particle was analyzed with respect to the following parameters: position range, phase switch rate, lifetime of each phase, and number of pause sites.

The mean squared displacement (MSD) was calculated for all motile phases (short-range and long-range) using custom scripts in MATLAB:

$$
\operatorname{MSD}(n \Delta t)=\frac{1}{N-n} \sum_{i=1}^{N-n}\left(x_{i+n}-x_{i}\right)^{2}
$$

where $N$ is total number of frames in the phase, $n$ is the number of frames at a given time step, $\Delta t$ is the time increment of one frame, and $x_{i}$ is the particle position in the $i$ th frame $\mathrm{e}^{70}$. The diffusion coefficient $(D)$ was determined by fitting a linear model of one-dimensional diffusion to the MSD plots:

$$
\operatorname{MSD}(n \Delta t)=2 D(n \Delta t)+y
$$

where $y$ is a constant ( $y$-intercept). Fittings resulting in $R^{2}$ less than 0.8 or using less than $10 \%$ of the MSD plot were not considered.

Reporting summary. Further information on research design is available in the Nature Research Reporting Summary linked to this article.

\section{Data availability}

All data are available from the corresponding author upon reasonable request.

\section{Code availability}

Custom MATLAB scripts are available from the corresponding author upon reasonable request.

Received: 11 June 2019; Accepted: 16 February 2020; Published online: 13 March 2020

\section{References}

1. Friedberg, E. C. et al. DNA repair: from molecular mechanism to human disease. DNA Repair 5, 986-996 (2006).

2. Van Houten, B. \& Kong, M. in Encyclopedia of Cell Biology, Vol. 1 (eds. Ralph A. Bradshaw \& Philip D. Stahl) 435-441 (Academic Press, 2016).

3. Sugasawa, K. Molecular mechanisms of DNA damage recognition for mammalian nucleotide excision repair. DNA Repair 44, 110-117 (2016).

4. Epanchintsev, A. et al. Cockayne's syndrome A and B proteins regulate transcription arrest after genotoxic stress by promoting ATF3 degradation. Mol. Cell 68, 1054-1066 e1056 (2017).

5. Bukowska, B. \& Karwowski, B. T. Actual state of knowledge in the field of diseases related with defective nucleotide excision repair. Life Sci. 195, 6-18 (2018).

6. Robins, P., Jones, C. J., Biggerstaff, M., Lindahl, T. \& Wood, R. D Complementation of DNA repair in xeroderma pigmentosum group A cell extracts by a protein with affinity for damaged DNA. EMBO J. 10, 3913-3921 (1991).

7. Reardon, J. T. \& Sancar, A. Recognition and repair of the cyclobutane thymine dimer, a major cause of skin cancers, by the human excision nuclease. Genes Dev. 17, 2539-2551 (2003).

8. Brown, K. L. et al. Binding of the human nucleotide excision repair proteins $\mathrm{XPA}$ and XPC/HR23B to the 5R-thymine glycol lesion and structure of the 
cis- $(5 R, 6 \mathrm{~S})$ thymine glycol epimer in the 5'-GTgG-3' sequence: destabilization of two base pairs at the lesion site. Nucleic Acids Res. 38, 428-440 (2010).

9. Liu, Y. et al. Cooperative interaction of human XPA stabilizes and enhances specific binding of XPA to DNA damage. Biochemistry 44, 7361-7368 (2005).

10. Koch, S. C. et al. Structural insights into the recognition of cisplatin and AAFdG lesion by Rad14 (XPA). Proc. Natl Acad. Sci. USA 112, 8272-8277 (2015).

11. Kuraoka, I. et al. Identification of a damaged-DNA binding domain of the XPA protein. Mutat. Res. 362, 87-95 (1996).

12. Buschta-Hedayat, N., Buterin, T., Hess, M. T., Missura, M. \& Naegeli, H. Recognition of nonhybridizing base pairs during nucleotide excision repair of DNA. Proc. Natl Acad. Sci. USA 96, 6090-6095 (1999).

13. Missura, M. et al. Double-check probing of DNA bending and unwinding by XPA-RPA: an architectural function in DNA repair. EMBO J. 20, 3554-3564 (2001).

14. Camenisch, U., Dip, R., Schumacher, S. B., Schuler, B. \& Naegeli, H. Recognition of helical kinks by xeroderma pigmentosum group A protein triggers DNA excision repair. Nat. Struct. Mol. Biol. 13, 278-284 (2006).

15. Sugitani, N., Voehler, M. W., Roh, M. S., Topolska-Wos, A. M. \& Chazin, W. J. Analysis of DNA binding by human factor xeroderma pigmentosum complementation group A (XPA) provides insight into its interactions with nucleotide excision repair substrates. J. Biol. Chem. 292, 16847-16857 (2017).

16. Yang, Z. et al. Specific and efficient binding of xeroderma pigmentosum complementation group A to double-strand/single-strand DNA junctions with 3'- and/or 5'-ssDNA branches. Biochemistry 45, 15921-15930 (2006).

17. Wakasugi, M. \& Sancar, A. Order of assembly of human DNA repair excision nuclease. J. Biol. Chem. 274, 18759-18768 (1999).

18. Nocentini, S., Coin, F., Saijo, M., Tanaka, K. \& Egly, J. M. DNA damage recognition by XPA protein promotes efficient recruitment of transcription factor II H. J. Biol. Chem. 272, 22991-22994 (1997).

19. Park, C. H., Mu, D., Reardon, J. T. \& Sancar, A. The general transcriptionrepair factor TFIIH is recruited to the excision repair complex by the XPA protein independent of the TFIIE transcription factor. J. Biol. Chem. 270, 4896-4902 (1995).

20. Li, C. L. et al. Tripartite DNA lesion recognition and verification by XPC, TFIIH, and XPA in nucleotide excision repair. Mol. Cell 59, 1025-1034 (2015).

21. Kokic, G. et al. Structural basis of TFIIH activation for nucleotide excision repair. Nat. Commun. 10, 2885 (2019).

22. Volker, M. et al. Sequential assembly of the nucleotide excision repair factors in vivo. Mol. Cell 8, 213-224 (2001).

23. Sugitani, N., Sivley, R. M., Perry, K. E., Capra, J. A. \& Chazin, W. J. XPA: A key scaffold for human nucleotide excision repair. DNA Repair 44, 123-135 (2016).

24. Li, L., Lu, X., Peterson, C. A. \& Legerski, R. J. An interaction between the DNA repair factor XPA and replication protein A appears essential for nucleotide excision repair. Mol. Cell Biol. 15, 5396-5402 (1995).

25. Camenisch, U. \& Nageli, H. XPA gene, its product and biological roles. Adv. Exp. Med. Biol. 637, 28-38 (2008).

26. Lin, J. J. \& Sancar, A. (A)BC excinuclease: the Escherichia coli nucleotide excision repair enzyme. Mol. Microbiol. 6, 2219-2224 (1992).

27. Iakoucheva, L. M. et al. Identification of intrinsic order and disorder in the DNA repair protein XPA. Protein Sci. 10, 560-571 (2001).

28. Buchko, G. W., Ni, S., Thrall, B. D. \& Kennedy, M. A. Structural features of the minimal DNA binding domain (M98-F219) of human nucleotide excision repair protein XPA. Nucleic Acids Res. 26, 2779-2788 (1998).

29. Fadda, E. Role of the XPA protein in the NER pathway: a perspective on the function of structural disorder in macromolecular assembly. Comput. Struct. Biotechnol. J. 14, 78-85 (2016).

30. Sugitani, N., Shell, S. M., Soss, S. E. \& Chazin, W. J. Redefining the DNAbinding domain of human XPA. J. Am. Chem. Soc. 136, 10830-10833 (2014).

31. Buchko, G. W. et al. Interactions of human nucleotide excision repair protein XPA with DNA and RPA70 Delta C327: chemical shift mapping and 15N NMR relaxation studies. Biochemistry 38, 15116-15128 (1999).

32. Ikegami, T. et al. Solution structure of the DNA- and RPA-binding domain of the human repair factor XPA. Nat. Struct. Biol. 5, 701-706 (1998).

33. Lian, F. M., Yang, X., Yang, W., Jiang, Y. L. \& Qian, C. Structural characterization of the redefined DNA-binding domain of human XPA. Biochem. Biophys. Res. Commun. https://doi.org/10.1016/j.bbrc.2019.05.050 (2019).

34. Ebert, C., Simon, N., Schneider, S. \& Carell, T. Structural insights into the recognition of $\mathrm{N}(2)$-Aryl- and C8-Aryl DNA lesions by the repair protein XPA/Rad14. Chembiochem 18, 1379-1382 (2017).

35. Yang, Z. G., Liu, Y., Mao, L. Y., Zhang, J. T. \& Zou, Y. Dimerization of human XPA and formation of XPA2-RPA protein complex. Biochemistry 41, 13012-13020 (2002)

36. Li, L., Elledge, S. J., Peterson, C. A., Bales, E. S. \& Legerski, R. J. Specific association between the human DNA repair proteins XPA and ERCC1. Proc. Natl Acad. Sci. USA 91, 5012-5016 (1994).

37. von Hippel, P. H. \& Berg, O. G. On the specificity of DNA-protein interactions. Proc. Natl Acad. Sci. USA 83, 1608-1612 (1986).
38. Yang, Y., Sass, L. E., Du, C., Hsieh, P. \& Erie, D. A. Determination of proteinDNA binding constants and specificities from statistical analyses of single molecules: MutS-DNA interactions. Nucleic Acids Res. 33, 4322-4334 (2005).

39. Beckwitt, E. C., Kong, M. \& Van Houten, B. Studying protein-DNA interactions using atomic force microscopy. Semin Cell Dev. Biol. 73, 220-230 (2018).

40. Kaemmer, S. B. Introduction to Bruker's Scanasyst and Peakforce Tapping AFM Technology. Bruker Application Note. (Bruker Nano Inc., Santa Barbara, 2011).

41. Pyne, A., Thompson, R., Leung, C., Roy, D. \& Hoogenboom, B. W. Singlemolecule reconstruction of oligonucleotide secondary structure by atomic force microscopy. Small 10, 3257-3261 (2014)

42. Kong, M. et al. Single-molecule imaging reveals that Rad4 employs a dynamic DNA damage recognition process. Mol. Cell 64, 376-387 (2016)

43. Iakoucheva, L. M. et al. Aberrant mobility phenomena of the DNA repair protein XPA. Protein Sci. 10, 1353-1362 (2001).

44. Datta, H. J., Chan, P. P., Vasquez, K. M., Gupta, R. C. \& Glazer, P. M. Triplexinduced recombination in human cell-free extracts. Dependence on XPA and HsRad51. J. Biol. Chem. 276, 18018-18023 (2001).

45. Rademakers, $\mathrm{S}$. et al. Xeroderma pigmentosum group A protein loads as a separate factor onto DNA lesions. Mol. Cell Biol. 23, 5755-5767 (2003).

46. Schneider, S. W., Larmer, J., Henderson, R. M. \& Oberleithner, H. Molecular weights of individual proteins correlate with molecular volumes measured by atomic force microscopy. Pflug. Arch. 435, 362-367 (1998).

47. Ratcliff, G. C. \& Erie, D. A. A novel single-molecule study to determine protein - protein association constants. J. Am. Chem. Soc. 123, 5632-5635 (2001).

48. Pratto, F., Suzuki, Y., Takeyasu, K. \& Alonso, J. C. Single-molecule analysis of protein-DNA complexes formed during partition of newly replicated plasmid molecules in Streptococcus pyogenes. J. Biol. Chem. 284, 30298-30306 (2009).

49. O'Handley, S. F. et al. Structural characterization of an N-acetyl-2aminofluorene (AAF) modified DNA oligomer by NMR, energy minimization, and molecular dynamics. Biochemistry 32, 2481-2497 (1993).

50. Grad, R., Shapiro, R., Hingerty, B. E. \& Broyde, S. A molecular mechanics and dynamics study of the minor adduct between DNA and the carcinogen 2(acetylamino)fluorene (dG-N2-AAF). Chem. Res. Toxicol. 10, 1123-1132 (1997).

51. Kad, N. M., Wang, H., Kennedy, G. G., Warshaw, D. M. \& Van Houten, B. Collaborative dynamic DNA scanning by nucleotide excision repair proteins investigated by single- molecule imaging of quantum-dot-labeled proteins. Mol. Cell 37, 702-713 (2010).

52. Dunn, A. R., Kad, N. M., Nelson, S. R., Warshaw, D. M. \& Wallace, S. S. Single Qdot-labeled glycosylase molecules use a wedge amino acid to probe for lesions while scanning along DNA. Nucleic Acids Res. 39, 7487-7498 (2011).

53. Ghodke, H. et al. Single-molecule analysis reveals human UV-damaged DNAbinding protein (UV-DDB) dimerizes on DNA via multiple kinetic intermediates. Proc. Natl Acad. Sci. USA 111, E1862-E1871 (2014).

54. Kim, J. K., Patel, D. \& Choi, B. S. Contrasting structural impacts induced by cis-syn cyclobutane dimer and (6-4) adduct in DNA duplex decamers: implication in mutagenesis and repair activity. Photochem. Photobio. 62, 44-50 (1995).

55. Kong, M., Beckwitt, E. C., Springall, L., Kad, N. M. \& Van Houten, B. Singlemolecule methods for nucleotide excision repair: building a system to watch repair in real time. Methods Enzymol. 592, 213-257 (2017).

56. Liu, L. et al. PARP1 changes from three-dimensional DNA damage searching to one-dimensional diffusion after auto-PARylation or in the presence of APE1. Nucleic Acids Res. 45, 12834-12847 (2017).

57. Berg, O. G., Winter, R. B. \& von Hippel, P. H. Diffusion-driven mechanisms of protein translocation on nucleic acids. 1. Models Theory Biochem. 20, 6929-6948 (1981)

58. Tafvizi, A., Huang, F., Fersht, A. R., Mirny, L. A. \& van Oijen, A. M. A singlemolecule characterization of p53 search on DNA. Proc. Natl Acad. Sci. USA 108, 563-568 (2011).

59. $\mathrm{Mu}, \mathrm{H}$. et al. Nucleotide excision repair of 2-acetylaminofluorene- and 2aminofluorene-(C8)-guanine adducts: molecular dynamics simulations elucidate how lesion structure and base sequence context impact repair efficiencies. Nucleic Acids Res. 40, 9675-9690 (2012).

60. Lin, J. et al. Functional interplay between SA1 and TRF1 in telomeric DNA binding and DNA-DNA pairing. Nucleic Acids Res. 44, 6363-6376 (2016).

61. Cheon, N. Y., Kim, H. S., Yeo, J. E., Scharer, O. D. \& Lee, J. Y. Single-molecule visualization reveals the damage search mechanism for the human NER protein XPC-RAD23B. Nucleic Acids Res. 47, 8337-8347 (2019).

62. Slutsky, M. \& Mirny, L. A. Kinetics of protein-DNA interaction: facilitated target location in sequence-dependent potential. Biophys. J. 87, 4021-4035 (2004).

63. Mirny, L. et al. How a protein searches for its site on DNA: the mechanism of facilitated diffusion. J. Phys. A 42, 434013 (2009).

64. Tan, C., Terakawa, T. \& Takada, S. Dynamic coupling among protein binding, sliding, and DNA bending revealed by molecular dynamics. J. Am. Chem. Soc. 138, 8512-8522 (2016). 
65. Schaefer, C. M. et al. FadA5 a thiolase from Mycobacterium tuberculosis: a steroid-binding pocket reveals the potential for drug development against tuberculosis. Structure 23, 21-33 (2015).

66. Sauer, F. et al. Differential oligomerization of the deubiquitinases USP25 and USP28 regulates their activities. Mol. Cell 74, 421-435 e410 (2019).

67. Schofield, M. J., Lilley, D. M. \& White, M. F. Dissection of the sequence specificity of the Holliday junction endonuclease CCE1. Biochemistry 37, 7733-7740 (1998).

68. Luo, J. et al. Optical control of DNA helicase function through genetic code expansion. Chembiochem 18, 466-469 (2017).

69. Wang, H., Nora, G. J., Ghodke, H. \& Opresko, P. L. Single molecule studies of physiologically relevant telomeric tails reveal POT1 mechanism for promoting G-quadruplex unfolding. J. Biol. Chem. 286, 7479-7489 (2011).

70. Nelson, S. R., Dunn, A. R., Kathe, S. D., Warshaw, D. M. \& Wallace, S. S. Two glycosylase families diffusively scan DNA using a wedge residue to probe for and identify oxidatively damaged bases. Proc. Natl Acad. Sci. USA 111, E2091-E2099 (2014)

\section{Acknowledgements}

The authors wish to thank Samuel Wilson for providing purified His-Pol $\beta$ and His-APE1 and Lili Liu for providing Nick ${ }_{514}$ and purified His-UvrD. The authors also thank Muwen Kong for helpful discussions and training, Neil Kad and Hong Wang for helpful discussions, and Namrata Kumar for careful reading of the manuscript. This work was supported by the National Institutes of Health [R01ES019566 to B.V.H., R01ES028686 to B.V.H., T32GM088119 to E.C.B., and 2P30CA047904 to UPMC Hillman Cancer Center]; Deutsche Forschungsgemeinschaft [SFB-1361, TP2-Carell].

\section{Author contributions}

E.C.B. and B.V.H. conceived the research. E.C.B. and S.J. performed all DNA tightrope experiments. E.C.B. performed all AFM experiments. E.C.B. and I.C.D. analyzed all singlemolecule data. E.C.B. and S.J. performed and analyzed all EMSA experiments. J.K., C.K. and F.S. performed and analyzed SEC-MALS experiments. E.C.B., S.J., J.K., J.B., N.S., and T.C. purified protein and DNA substrates. S.C.W. provided imaging resources. E.C.B. and B.V.H. drafted the paper, which was reviewed, discussed, and edited by all authors.

\section{Competing interests}

The authors declare no competing interests.

\section{Additional information}

Supplementary information is available for this paper at https://doi.org/10.1038/s41467020-15168-1.

Correspondence and requests for materials should be addressed to B.V.H.

Peer review information Nature Communications thanks Walter Chazin, Elisa Fadda and Ingrid Tessmer for their contribution to the peer review of this work. Peer reviewer reports are available.

Reprints and permission information is available at http://www.nature.com/reprints

Publisher's note Springer Nature remains neutral with regard to jurisdictional claims in published maps and institutional affiliations.

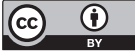

Open Access This article is licensed under a Creative Commons Attribution 4.0 International License, which permits use, sharing, adaptation, distribution and reproduction in any medium or format, as long as you give appropriate credit to the original author(s) and the source, provide a link to the Creative Commons license, and indicate if changes were made. The images or other third party material in this article are included in the article's Creative Commons license, unless indicated otherwise in a credit line to the material. If material is not included in the article's Creative Commons license and your intended use is not permitted by statutory regulation or exceeds the permitted use, you will need to obtain permission directly from the copyright holder. To view a copy of this license, visit http://creativecommons.org/ licenses/by/4.0\%

(C) The Author(s) 2020 